\title{
Characterisation of cross-flow above a railway bridge equipped with solid windbreaks
}

\author{
S. Avila-Sanchez ${ }^{\text {a,* }}$, O. Lopez-Garcia ${ }^{a}$, A. Cuerva ${ }^{a}$, J. Meseguer ${ }^{b}$
}

\begin{abstract}
A B S T R A C T
The flow field above a two dimensional model of a railway bridge equipped with solid windbreaks is analysed in a wind tunnel. Particle image velocimetry (PIV) is used to measure the flow velocity in planes perpendicular to the bridge span. The mean velocity components, the two-component turbulent kinetic energy, the turbulence intensities of the velocity fluctuation components and the Reynolds shear stress above the bridge deck are presented. The flow patterns based on the streamlines of the average flow field are analysed. The inclusion of a windbreak produces a separation bubble, that is locked to the bridge deck due to presence of the leeward fence. Special attention is paid to the analysis of the flow field characteristics along the vertical profiles above the railway tracks. The inclusion of the windbreak leads both to an increase of the mean velocity and the turbulence intensity around the catenary contact wires. On the other hand, the flow in the region close to the bridge deck is slowed-down. The effect of the size of the final interrogation window used in the PIV analysis is considered, more particularly on the determination of the mean velocity and turbulence intensity. The results show that a decrease of the final interrogation window leads to an increase of the turbulence intensity when there are no wind protection devices installed on the bridge.
\end{abstract}

\section{Introduction}

The interaction between wind and civil engineering structures has focused the attention of several studies since the XIX century $[1,2]$, since the safe operation of these last ones are strongly affected by wind loads. The railway transport system is an example of an infrastructure that is affected by wind actions. For instance, cross-wind can strongly compromise both the structural integrity and the safe operation of the rolling stock [3]. One of the most relevant problems is the wind-induced dynamics of the contact wires which are equipped by railway overheads. From the aerodynamic point of view such contact wires can be considered as noncircular cross-section cables [4] exposed to atmospheric turbulent flow. With regard to the characteristics of the wind-induced dynamics of contact-wires, it is known that wind actions on noncircular geometries could eventually trigger aeroelastic instabilities such as galloping phenomena [5-8]. In fact, Johnson [3] and Scanlon and Oldroyd [9] have extensively reported on the suscep- tibility to suffer undesirable wind-induced phenomena, of the cable system that composes the railway overhead. These phenomena have adverse effects on the operation of the system. For instance, under the effect of cross-winds, large amplitude oscillations due to cable galloping of railway overheads have lead to the delay and cancellation of train transits at several locations of Scotland [10] and the British East Coast Main Line [11].

On the other hand, cross-winds and the shape of both the vehicle and the surroundings are crucial factors on the resulting aerodynamic loads on trains [12]. These aerodynamic loads may lead to train overturning if the cross-wind speed reaches a threshold value, summarised in the Characteristic Wind Curve (CWC) [13], specially because train speeds have risen significantly over the last decades. The overturning risk increases when moving vehicles travel along exposed locations such as bridges or embankments. The wind speed in the atmospheric boundary layer normally grows as height increases, leaving aside the fact that at ground level there may be other elements which could eventually slow down the wind speed, such as vegetation. This increase in the risk of overturning has caught the attention of several studies, which have been focused on the characterisation of the aerodynamic response to cross-winds of either road vehicles [14-19] or rolling stock [20-26] travelling on bridges. 
One of the most effective ways to alleviate the adverse effects of cross-wind loads is by placing windbreaks (also named parapets) upstream the elements to be protected. Windbreaks have been and still are extensively studied because of their use in agriculture [27-30], wind-erosion control [31-33] and reduction of wind loading on civil engineering structures [34-37], amongst other applications. Traffic safety and comfort can also be improved by the use of such wind protection devices. Some efforts have been paid to analyse the effectiveness of parapets to protect trains and other vehicles from cross-wind effects [20,38-40]. Provided the parapet is high enough, experimental results show that very drastic reduction of the wind load coefficients on the train model can be obtained. Also experimental results existing in the literature evidence that the addition of eaves to the parapets improves the shelter effect of the windbreaks [20]. Unfortunately, these elements can induce modifications of the flow field that could lead to the appearance of additional undesirable wind loads on the railway overhead.

The flow around a bridge deck, either with or without parapets, is driven by flow separation. The flow separates at the upper windward edge of an empty bridge without wind barriers $[20,41]$. The flow reattachment position is influenced both by the wind incidence angle, as well as turbulence, i.e. for stronger freestream turbulence the flow reattaches closer to the bridge leading edge. The resulting shear layer can reattach on the bridge deck forming a recirculation bubble, provided the angle of incidence of the flow is small enough. A thinner wake downstream the bridge appears when the reattachment occurs, because a second flow separation occurs at the leeward edges. When the railway bridge is equipped with solid windbreaks, the flow separation takes place at the upper edge of the windbreak, and the vertical distance of the shear layer to the deck increases accordingly. The inclusion of eaves at the windbreak tip boosts this effect [41]. If the parapet is high enough, the resulting shear layer can impinge the catenary, increasing the turbulence intensity at the contact wire locations [42]. Scanlon and Oldroyd [9] pointed out that the increment of turbulence intensity (and the modification of the flow field in general) at the location of the contact wires, due to the presence of windbreaks, is of great interest in order to provide a more detailed description of the cable galloping phenomenon.

Over the past few decades several studies have been devoted to analyse the shelter efficiency of windbreaks and shelterbelts. In general, three different approaches have been adopted in order to characterise the shelter efficiency of windbreaks. The first approach consists on the characterisation of the effect induced on an obstacle downstream the fence, such as the wind tunnel analysis of the wind driven erosion on a triangular hill made of sand particles, described in [32], or the determination of the aerodynamic coefficients of a train model exposed to cross-flow conditions, presented in [43]. The second approach consists in quantifying the drag coefficient of the windbreak $[44,45]$. The third approach relies on the characterisation of the flow field downstream the windbreak. This flow field characterisation has been conducted either by means of full-scale measurements [30,4648], either by tests in wind tunnel [49-53] or by means of computational simulations [31,53-58].

A large variety of experimental techniques has been used in order to characterise the flow properties downstream of the windbreaks. For instance, Cornelis and Gabriels [59] and Dierickx et al. [60] used full-scale measurements from vane probes installed at several locations, in order to determine the modification of the wind velocity field induced by the inclusion of a windbreak. Other full-scale experimental techniques include the use of cup and sonic anemometers $[47,48,61]$. With regard to wind tunnel testing, particle tracking velocimetry (PTV) [62], flow visualisation of the commencement of sand particle motion [32], hot-wire anemometry
[46,63] and particle image velocimetry (PIV) $[49,50,64-66]$ have been applied.

There exist some discrepancies concerning the sheltering efficiency between the different studies, because the wind velocity reduction and the turbulence intensity increase are directly related to both the windbreak design and the incoming flow characteristics. The flow properties downstream the windbreak are influenced by its porosity, shape, orientation and the distance to the obstacle. For a given windbreak height, the design parameter which is considered to have the main influence on the wind properties downstream the windbreak is the porosity, defined as the ratio of the open area of the windbreak to its frontal area. It is widely accepted that low porosity values produce higher wind velocity reductions close to the parapet, inside its wake, but also that the increment of turbulence intensity downstream the windbreak decreases as porosity increases $[48-50,54]$. Although low porosity fences produce larger mean wind speed reductions, the flow region affected by the windbreak may be smaller due to a stronger recirculation and a reduced size of the separation bubble.

In order to optimise the shelter effect provided by the windbreak design, a basic understanding on the basic flow patterns taking place upwind and downwind a two-dimensional windbreak may be useful. These flow patterns, already described by several authors $[57,67,68]$, are schematized in Fig. 1 . The flow in the region (A) is mainly driven by the undisturbed freestream velocity. The windbreak is idealised as a solid boundary that obstructs, and therefore displaces, the incoming flow (B). This flow is accelerated in the region immediately above the windbreak, close to the windbreak tip. The flow inside the wake downstream is decelerated by the windbreak. If there are no additional obstacles, this region is mixed with the outer flow, and the development of a new boundary layer is possible (E). Two interesting characteristics are pointed out in the conceptual sketch of the flow patterns. The first one, as described by Plate [67], is that solid windbreaks may lead to reverse flow regions in the mean velocity field and the appearance of a separation bubble (region $G$ ). The other one is associated to the appearance of small vortex-like structures $(F)$ in a region referred by Speckart and Pardyjak [57] as the bleed flow.

Plate [67] pointed out that the optimisation of the windbreak arrangement based on a particular requirement needs input information from several sources, such as the aerodynamics of the windbreak. In the present work, the investigation is focused on the flow properties around the catenary contact wire of a railway bridge section. The main concern of most of the windbreak studies has been the determination of the flow structure in the sheltered region, induced by the presence of windbreaks located upstream the region under study. In consequence, there is no much information on the wind characteristics in downstream locations where catenary contact wires are typically located. Nevertheless, it is fair to mention that Kozmar et al. $[64,65]$ studied by means of PIV technique in a wind tunnel, the characteristics of the flow above a model bridge section equipped with windbreaks at the leading edge. These authors reported an increment on the wind velocity with the windbreak porosity. Kwon et al. [39] focused on the design criteria in order to protect vehicles on an expressway. They provided a characterisation based on hot-wire anemometry of the shelter effect determined as the velocity magnitude reduction. Besides Kozmar et al. [64,65] and Kwon et al. [39], several authors have focused the interest on the effect induced by a single windbreak placed at the leading edge. For instance, Guo et al. [69] analysed the effect of the windbreak height and porosity on the aerodynamic coefficients of a static train model. He et al. [23] also included in their study the aerodynamic interference due to adjacent trains. He et al. [23] described that the separated flow from the top of a solid windbreak forms a trapped vortex on the deck 


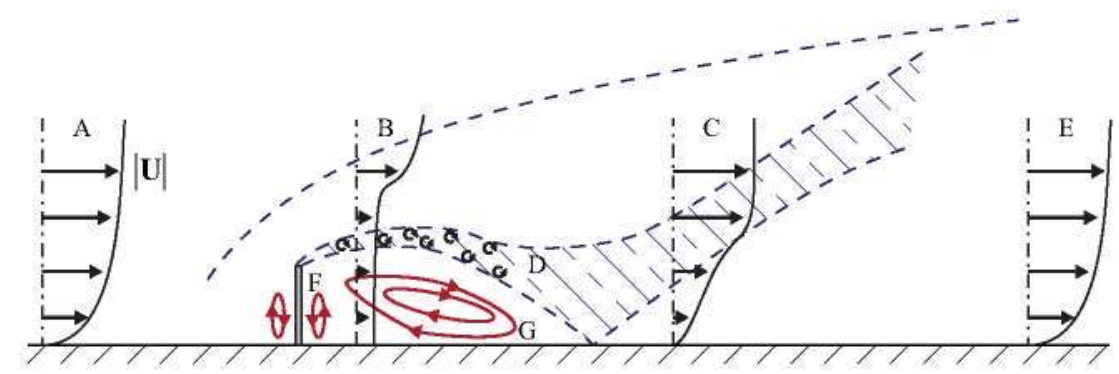

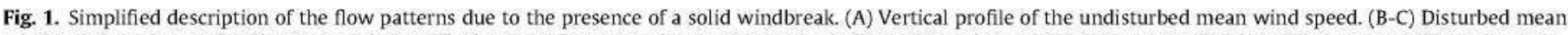

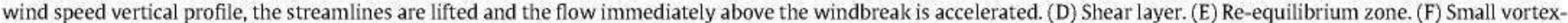
like structure in the bleed flow. (G) Reverse cell. Adapted from Plate [67], Speckart and Pardyjak [57] and Sanz Andrés et al. [68].

of the bridge (similar effect to region G in Fig. 1). The inclusion of a windbreak on the trailing edge may prevent this vortex from being blown away from the bridge deck. However, under some scenarios there exist two dominant wind directions, for instance Sorribes et al. [61] observed at the 0 Eixo viaduct two prevailing wind directions almost perpendicular to the bridge span. In fact, the effect of the inclusion of two windbreaks on the bridge deck is still analysed from the perspective of both train safety $[22,70,71]$ and road vehicles safety [17]. Xiang et al. [70] also provide a vertical profile of pressure coefficient above the track middle point of a railway bridge and Zhu et al. [18] the profiles of mean wind speed over the four lanes of a flat box girder bridge.

In order to increase the information available about the flow topology above a railway bridge equipped with a couple of solid windbreaks, an experimental analysis based on PIV technique is herein proposed. The remainder of this work is organised as follows. In Section 2, the experimental set-up and the steps performed to process the experimental information are described. In Section 3, the characteristics of the flow above the railway bridge, based on the mean value of the velocity components and the turbulent kinetic energy are presented. Section 4 is focused on the wind speed reduction and the turbulence intensity modification in the vertical line that passes through the catenary contact wires. Finally some conclusions are presented in Section 5.

\section{Experimental set-up}

\subsection{Model description}

The experimental analysis herein presented is focused on the characterisation of the flow properties above a two-dimensional model of a double track railway bridge. The bridge model is subjected to cross-flow conditions, i.e.. the mean wind blows in the plane perpendicular to the longitudinal axis of the bridge. The cross-section reproduces the geometry of a few box girder bridges located along the Northwest of Spain, such as the bridge over the river "Ulla" [72] or the river "Deza" [73]. The model cross-section, which is the same as that described in $[42,74]$, is shown in Fig. 2. The model scale is $1 / 50 \mathrm{th}$. The bridge deck is $h_{\mathrm{b}}=65 \mathrm{~mm}$ high and $c_{\mathrm{b}}=280 \mathrm{~mm}$ wide. The distance from the symmetry plane to the track middle point is $I_{\mathrm{cw}}=55 \mathrm{~mm}$. The catenary contact wires are placed at $h_{\mathrm{cw}}=106 \mathrm{~mm}$ above the track middle points.

Two solid windbreaks with height $h_{\text {wb }}$ can be attached to both edges of the railway platform, as indicated in Fig. 2. The windbreaks may include a perpendicular eave with a length $a_{\mathrm{e}}$ on their tops. Three different configurations have been analysed, the bridge with no windbreaks ( $h_{\mathrm{wb}}=0 \mathrm{~mm}, a_{\mathrm{e}}=0 \mathrm{~mm}$ ), the bridge equipped with windbreaks ( $h_{\mathrm{wb}}=55 \mathrm{~mm}, a_{\mathrm{e}}=0 \mathrm{~mm}$ ), and the bridge with windbreaks equipped with a short eave $\left(h_{\mathrm{wb}}=55 \mathrm{~mm}, a_{\mathrm{e}}=5 \mathrm{~mm}\right)$.

The coordinate system used in the following analysis is also defined in Fig. 2. When the angle of incidence of the flow is $\alpha=0^{\circ}$, the $x_{1}$-axis direction is aligned with the mean wind direction and the $x_{3}$-axis with the vertical direction. Different values for the angle of incidence are simulated by turning the model about the $x_{2}$-axis. For the sake of simplicity, the coordinates presented in the experimental results will be referred to the bridge deck height, i.e.. $x_{1} / h_{\mathrm{b}}$ and $x_{3} / h_{\mathrm{b}}$.

In order to reproduce two-dimensional mean flow conditions and to mitigate boundary conditions effects on the model ends, a long span bridge model was built and flow measurements were taken in the middle section, see Fig. 3. The model length along the $x_{2}$-axis is approximately 5.7 times the bridge width. The bridge model was fixed to the wind tunnel floor by a couple of vertical supports. The distance from the bridge deck to the ground was $H / h_{\mathrm{b}} \simeq 5.7$, see Fig. 3 . This set-up guarantees that the test model is located out of the wind tunnel boundary layer region with height $\delta / h_{\mathrm{b}} \simeq 3.4$, where $\delta$ is the boundary layer thickness presented by [75], and therefore in a flow area with negligible mean velocity vertical gradient.

\subsection{Wind tunnel description}

The experiments were conducted in the ACLA16 wind tunnel (ACLA16WT), which is located at the IDR-UPM (Universidad Politécnica de Madrid). ACLA16WT is a open-return wind tunnel, with a closed test section. The straight test section is $2.2 \mathrm{~m}$ wide $\times 2.2 \mathrm{~m}$ high and $18 \mathrm{~m}$ long. The long fetch upstream the main test section allows the natural development of the wind tunnel boundary layer. The bridge-deck section was located in the region in which the mean flow characteristics can be assumed to remain uniform. Thus, the characterisation of the undisturbed freestream velocity at the main test section is not included here, although it has been presented by Yeow et al. [75] in their figure and Table I.

The wind tunnel is powered by 16 variable speed fans with a nominal output of $10 \mathrm{~kW}$ each one. The wind speed upstream is about $U_{\infty}=7 \mathrm{~m} / \mathrm{s}$, and the Reynolds number based on the bridge width is $\operatorname{Re}_{\mathrm{c}}=1.29 \times 10^{5}\left(\operatorname{Re}_{h_{b}}=0.30 \times 10^{5}\right)$. Raine and Stevenson [76] pointed out that, it has been traditionally assumed the independence of Reynolds number on the leeward flow patterns of bluff buddies such as fences or buildings. Although it has been observed that the aerodynamic behaviour of some civil engineering structures is Reynolds number dependent [77,78], there is not an agreement on a minimum Reynolds number above which the Reynolds number effect can be neglected. Nevertheless, the experiment set-up needs to conciliate two opposed practical requirements on the minimum Reynolds number. The first one, the model scale should be small enough both to create a long span model to mitigate boundary effects and to avoid blockage effects (less than $5 \%$ in the present study) [79]. The second requirement is to avoid unwanted oscillations on the CCD camera or the bridge model induced by a high freestream velocity. The Reynolds number chosen is a trade-off to fulfil both requirements. 


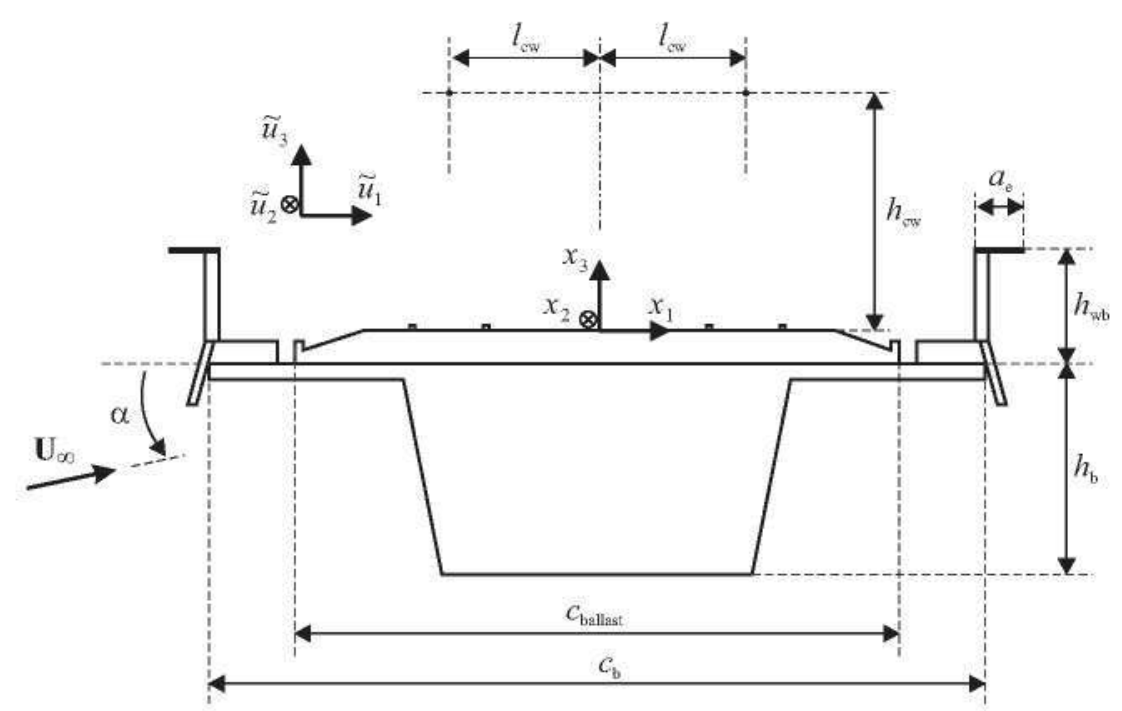

Fig. 2. Sketch of the railway bridge cross-section equipped with a ballast track. The bridge and ballast width are $c_{\mathrm{b}}=280 \mathrm{~mm}$ and $c_{\text {ballast }}=220 \mathrm{~mm}$, respectively. $h_{\mathrm{b}}$ is the bridge height.

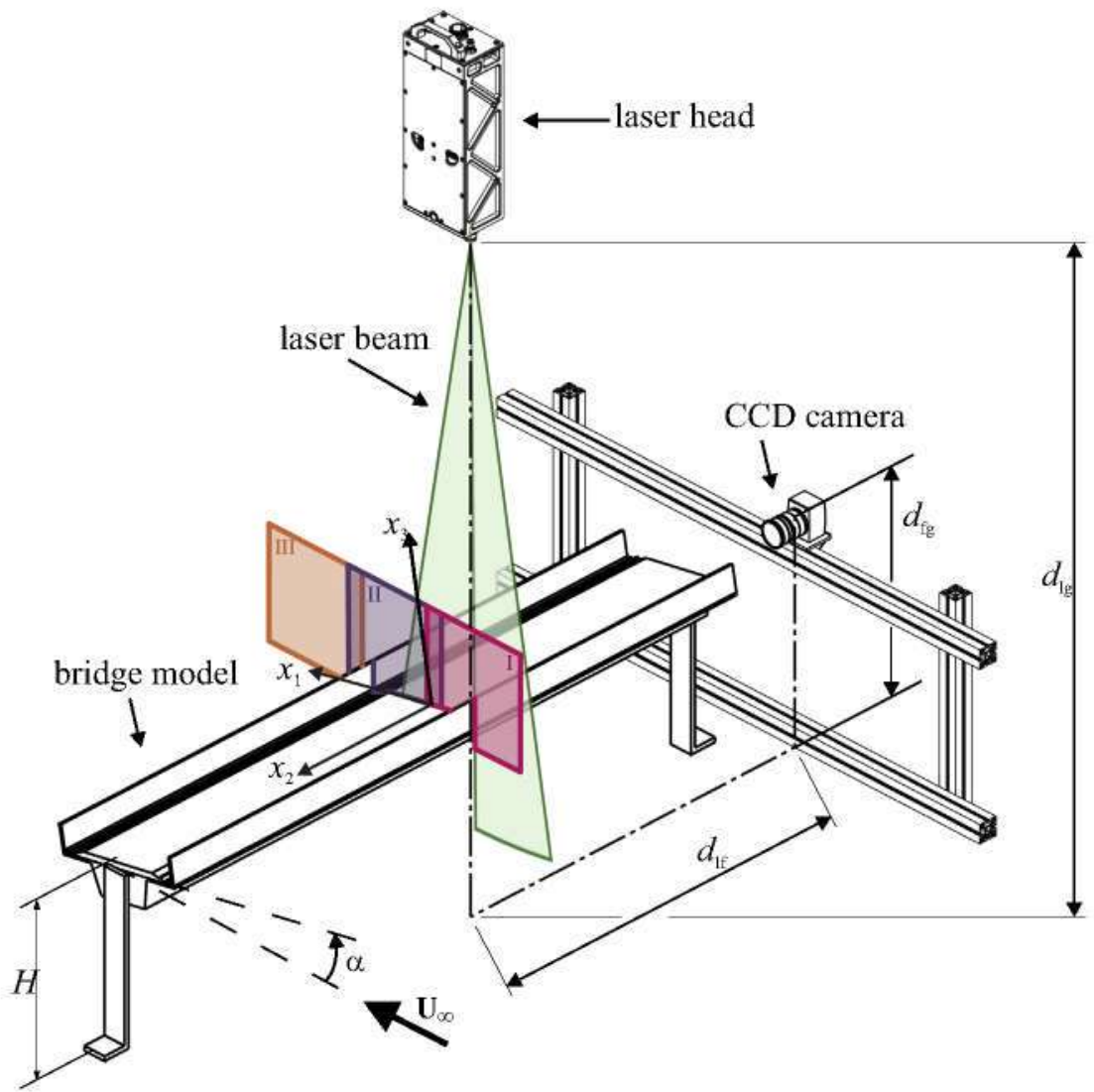

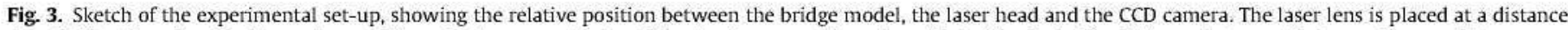

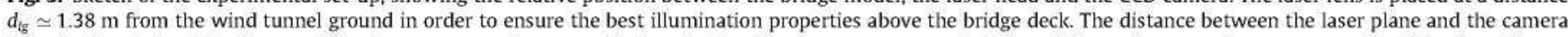

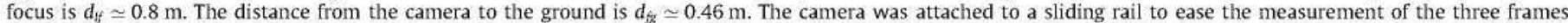
denoted as (I, II, III) in the sketch.

The PIV measurements were conducted by using a TSI Inc. setup. A dual pulsed laser Nd:YAG system (model EverGreen 200, manufactured by Quantel) illuminated the area of interest above the railway platform. The laser head was placed on an ISEL traverse system to ease its displacement. Most of the instrumentation was located outside the main conduct to reduce air flow distortion. Both a spherical and a cylindrical lenses were attached to the laser head nozzle to produce a light sheet between 1 and $2 \mathrm{~mm}$ thick. The lens installed on the laser head are designed to provide the desired laser sheet properties up to $1 \mathrm{~m}$ from the laser nozzle. 
Therefore the distance from the last lens to the ground is set to $1.380 \mathrm{~m}$, in order to ensure the best illumination properties above the bridge deck.

The air flow was seeded with Sebacate particles produced by a Laskin nozzle-based generator. The size of the particles was about $1 \mu \mathrm{m}$ diameter. The particle images were acquired via a chargecoupled device (CCD) camera, model POWERVIEW Plus 4M, with a $2048 \times 2048$ pixel resolution. A custom calibration target was used due to the cross-section shape of the model equipped with windbreaks. To improve contrast between Sebacate particles and background, the $C C D$ camera was equipped with a visible light polariser and the test section was darkened during the tests. Both, the laser and the camera were synchronised by a LASERPULSE Synchronizer (model 610035). Image acquisition and vector field processing were performed using Insight 4G software, provided by TSI.

The experimental set-up inside the wind tunnel is described in Fig. 3. The CCD camera was fixed to a stiff support $d_{\mathrm{fg}} \simeq 0.46 \mathrm{~m}$ $\left(d_{\mathrm{fg}} / h_{\mathrm{b}} \simeq 7.1\right)$ above the ground and was positioned at a focus distance $d_{\text {If }} \simeq 0.8 \mathrm{~m}\left(d_{\text {If }} / h_{\mathrm{b}} \simeq 12.3\right)$ from the laser beam. Three image frames were measured during the experimental tests (I, II and III in Fig. 3), with about $8 \%$ overlap.

A set of calibration images with the calibration plate placed on the bridge deck was acquired for each frame. The distance from the camera focus and the laser beam provided a resolution near to $102.5 \mu \mathrm{m} /$ pixel, i.e. $1 \mathrm{~mm}$ on real scale corresponds to around 9.75 pixels on the image plane. This configuration leads to particle image sizes about 3-4 pixels. The size of the captured field in each image frame is about $210 \times 210 \mathrm{~mm}$. A set of 1000 image pairs was recorded for each frame, using the frame straddling technique. The average intensity of each frame was subtracted from the set in order to improve the signal to noise ratio (SNR) where applying the cross-correlation algorithm [80]. The separation between laser pulses on the same image pair was $\Delta t=135 \mu \mathrm{s}$. The capture rate was set at around 3.63 image pairs per second. Taking as reference the velocity upstream the model, the separation between laser pulses yields a particle displacement about $25-30 \%$ of a 32 pixel by 32 pixel interrogation window size.

Each set of 1000 image-pairs was analysed to compute the instantaneous velocity vector fields. The spatial resolution of the velocity fields was increased by using an adaptive interrogation window. The first correlation calculation computed an initial vector field with a $64 \times 64$ pixel square interrogation window with a $50 \%$ overlap grid spacing. Three different final interrogation windows sizes were analysed, $32 \times 32$ pixels, $16 \times 16$ pixels, and $8 \times 8$ pixels. The interests to analyse this parametric dependence lays on its influence on one-point and two-point statistics, as reported by Henning and Ehrenfried [81] and by Lecordier et al. [82]. With this regard, Henning and Ehrenfried [81] pointed out that the velocity fluctuation decreases as the interrogation window increases, because the spatial averaging acts as a low pass filter. Lecordier et al. [82] explains that an increase in the interrogation window may lead to an underestimation of the velocity fluctuation, but at the same time the low number of particles in the smaller interrogation windows may overestimate the turbulence intensity. Although Lecordier et al. [82] also points out that these effects are reduced by the use of sub-pixel iterative PIV technique. The present analysis was based on Fast Fourier Transform (FFT) correlation algorithm, which provides a reasonable trade-off between computational time and precision. A Gaussian fit was used to ease the location of correlation peaks and to obtain subpixel resolution. To minimise the number of non-valid vectors, Rohaly-Hart Analysis (RHA) was enabled up to a $5 \times 5$ neighbour size, on those spots that failed the SNR validation test. Typically a number of invalid vectors below $1.7 \%$ was obtained.

\section{Insights on the flow topology based on the PIV characterisation}

In Table 1 the set of parameters that were considered during the tests is summarised. Three different angles of incidence of the flow, $\alpha$, and three different windbreak configurations were tested. Since the vector field was computed using three different final interrogation window sizes, a total of 27 different configurations were analysed. For the sake of briefness, unless stated otherwise, the herein presented experimental results correspond to the $16 \times 16$ pixels final interrogation window.

\subsection{Velocity components}

Let us consider the fluid motion above the middle section of the bridge deck (plane $x_{2}=0$, see Fig. 2). The reference point of the coordinate system lays in the symmetry plane of the bridge deck, just on top of the ballast. The local flow velocity $\tilde{\mathbf{u}}(\mathbf{x})=\left(\tilde{u}_{1}, \tilde{u}_{2}, \tilde{u}_{3}\right)$ at the location $\mathbf{x}=\left(x_{1}, 0, x_{3}\right)$ will be referred as $\tilde{\mathbf{u}}$ to simplify notation. The wind velocity time series are assumed to behave as a stationary ergodic process. Reynolds decomposition is applied to the velocity field. The velocity fluctuation $\mathbf{u}$ is expressed as

$\mathbf{u}=\tilde{\mathbf{u}}-\mathbf{U}$

where $\mathbf{U}=\left(U_{1}, U_{2}, U_{3}\right)$ is the time averaged velocity.

The time averaged value of the longitudinal wind velocity component normalised with the upstream wind speed $U_{1} / U_{\infty}$ is shown in Fig. 4. When the windbreaks are installed, the detachment point of the shear layer moves from the edge of the platform to the top of the windbreak. An expected phenomenon that can be quantified is that, as the angle of incidence of the upstream flow increases, the wake produced by the fence is shifted upwards. As a consequence, the distance from the shear layer to the bridge deck increases, and a larger area above the railway platform experiences the sheltering effect provided by the windbreak. When the angle of incidence increases towards non-negative values, i.e. $\alpha \geqslant 0$, a reverse flow region in the mean velocity field (negative value of the mean averaged longitudinal velocity component, $U_{1} / U_{\infty}$ ) appears near to the leeward windbreak.

The distance from the contact wire to the ballast is about $x_{3}=h_{\mathrm{cw}} / h_{\mathrm{b}} \simeq 1.63$, see Fig. 2 . Both contact wires are located at $\left|x_{1}\right|=l_{c w} / h_{\mathrm{b}} \simeq 0.85$ from the symmetry plane. As can be observed in Fig. 4, for those cases with windbreaks installed and angles of flow incidence $\alpha=0^{\circ}$ and $\alpha=6^{\circ}$, the shear layer evolving from the detachment point on top of the windward windbreak reaches the region where the leeward contact wire is located. The shear layer is characterised by large gradients of the mean velocity components. If the angle of incidence is large enough the shear layer will flow above the contact wire location, for example in the case of the bridge equipped with windbreaks and flow incidence angle $\alpha=6^{\circ}$ the leeward contact wire is located inside a reverse flow region.

The time averaged value of the vertical component of the wind velocity, $U_{3} / U_{\infty}$, is shown in Fig. 5. As expected, the flow is

Table 1

List of parameters analysed in the PIV tests.

\begin{tabular}{|c|c|}
\hline Parameter & Values \\
\hline $\begin{array}{l}\text { Angle of incidence of the } \\
\text { flow, } \alpha\end{array}$ & $-6^{\circ}, 0^{\circ}, 6^{\circ}$ \\
\hline Windbreak model & $\begin{array}{l}\text { No windbreak, windbreak without eave and } \\
\text { windbreak with eave }\end{array}$ \\
\hline $\begin{array}{c}\text { Final interrogation } \\
\text { window }\end{array}$ & $32 \times 32,16 \times 16$ and $8 \times 8$ pixels \\
\hline
\end{tabular}



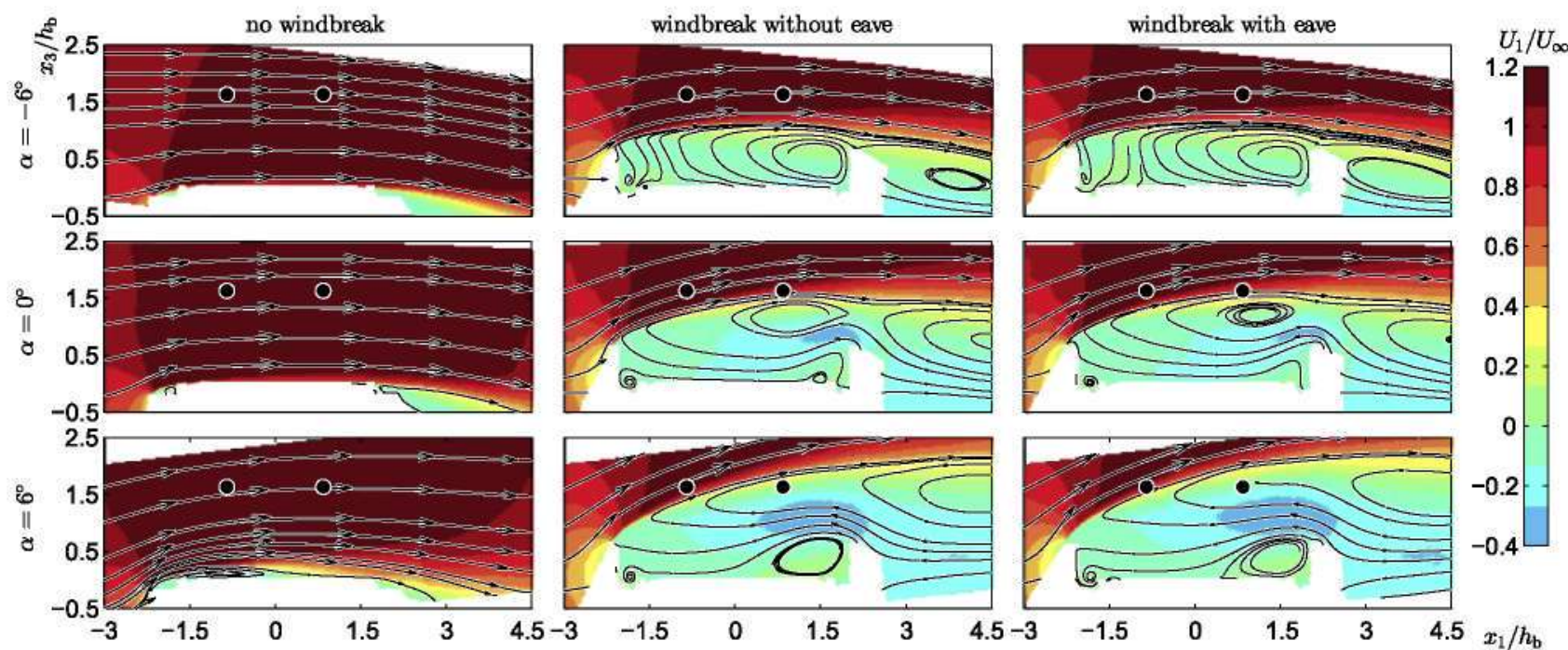

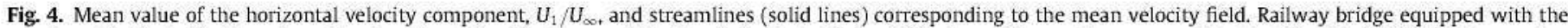

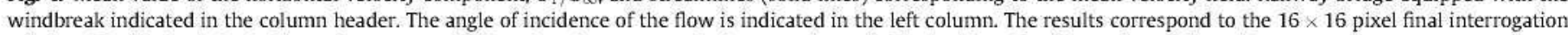
window. The black circles indicate the contact wire locations (not present during experiments). The incident flow blows from left to right.
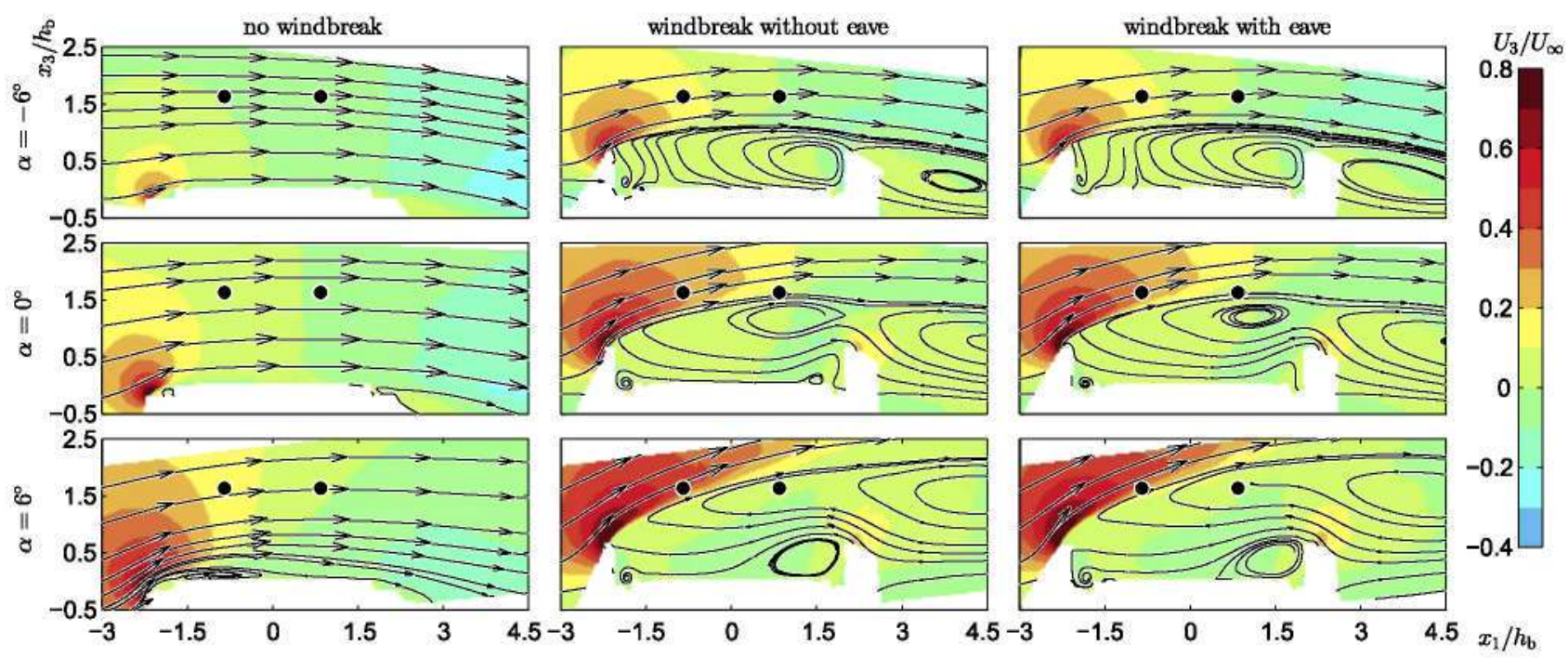

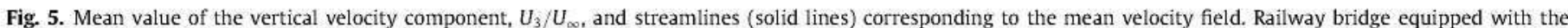

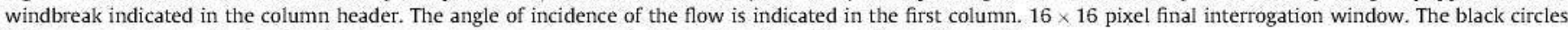
indicate the contact wire locations (not present during experiments). The incident flow blows from left to right.

deflected close to the leading edge of the model. When the model is not equipped with windbreaks, this deflection leads to an increase in this velocity component with an increase in the angle of incidence in the region around the leading edge. When the model is equipped with windbreaks, the vertical flow velocity component experiences an increase in the upstream region near to the detachment point, located at the upper side of the windward windbreak.

The inclusion of the eave on the windbreak, see Figs. 4 and 5, seems to have a negligible effect on the qualitative trends exhibited by the mean averaged values of the velocity components.

\subsection{Turbulent kinetic energy and Reynolds shear stress}

The values of the turbulent kinetic energy (TKE) and the Reynolds shear stress obtained from the PIV measurements are presented in this subsection. The standard PIV method used in the current analysis presents one main limitation since only the in-plane velocity components, $\tilde{u}_{1}$ and $\tilde{u}_{3}$, are resolved due to the use of the mono-PIV technique. Therefore, although the twodimensional set-up guarantees that the mean lateral component of the wind velocity is $U_{2}=0$, the fluctuation of this lateral component is $u_{2} \neq 0$, and no statistics involving fluctuation $u_{2}$ can be resolved.

\subsubsection{Two component turbulent kinetic energy, $\bar{k}_{2 \mathrm{C}}$}

The logarithmic value of the two component turbulent kinetic energy per unit mass density, $\bar{k}_{2 \mathrm{C}} / U_{\infty}^{2}$, calculated as

$\bar{k}_{2 C}=\frac{1}{2}\left(\overline{u_{1}^{2}}+\overline{u_{3}^{2}}\right)$

is shown in Fig. 6. The $\log \left(\bar{k}_{2 \mathrm{c}}\right)$ has been chosen since this representation allows to better distinguish the spatial variations of $\bar{k}_{2 \mathrm{c}}$. The $\bar{k}_{2 c} / U_{\infty}^{2}$ provides information about the averaged intensity of the velocity fluctuations in the flow. The separated shear layers 

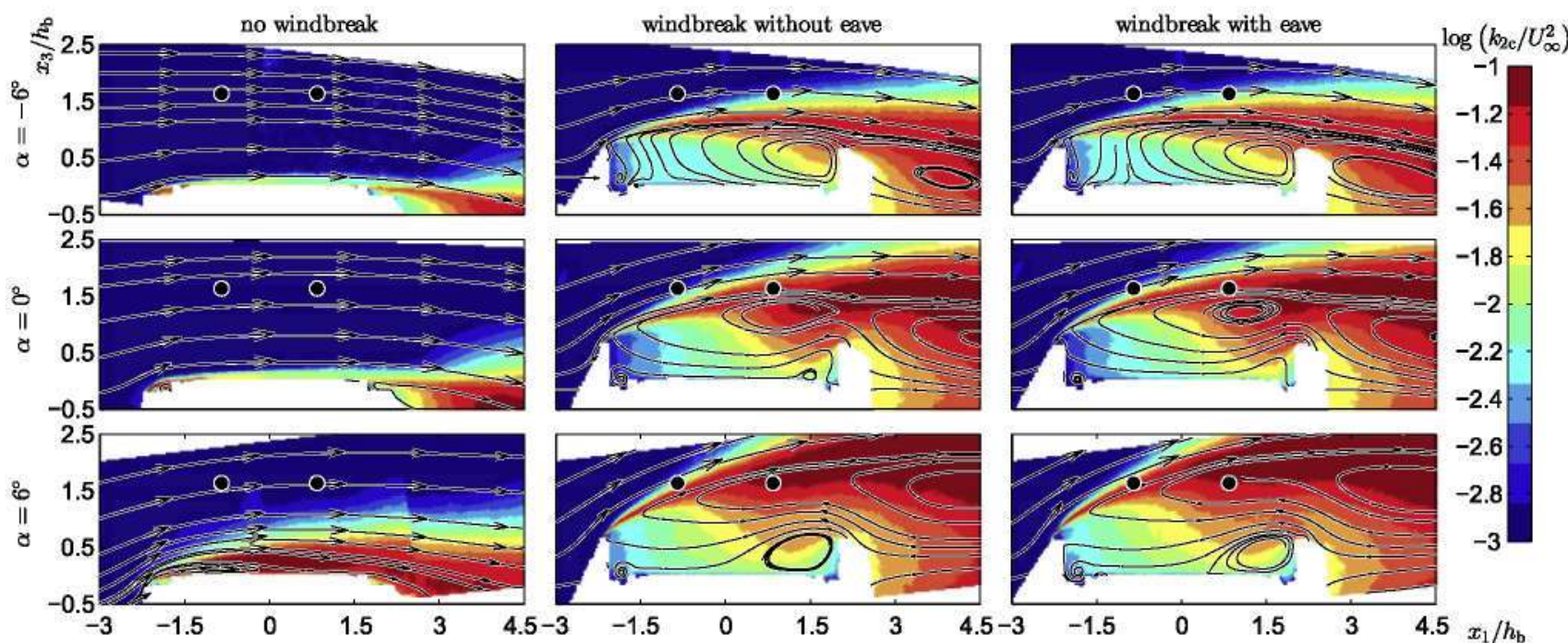

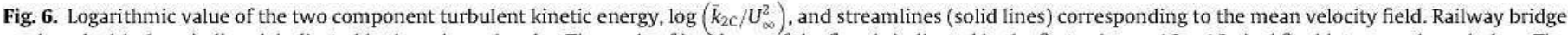

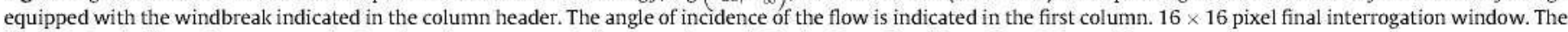
black circles indicate the contact wire locations (not present during experiments). The incident flow blows from left to right.

developed from the detachment points are characterised by high values of the two component TKE. The regions with high values of the $\bar{k}_{2 \mathrm{C}} / U_{\infty}^{2}$ are coincident with those with large gradients of the mean longitudinal velocity component shown in Fig. 4. In consequence, for certain configurations (windbreaks installed and $\alpha=0^{\circ}$ and $\alpha=6^{\circ}$ ) the leeward contact wire is immersed in a flow region with high values of turbulent kinetic energy. Although in the previous section, the influence of the eave on the mean values of the velocity components seems to be negligible, it can be observed that, when the angle of incidence of the flow is $\alpha=6^{\circ}$, the inclusion of the eave shifts the shear layer upwards, just enough for the windward contact wire to be also immersed in the flow region with high values of turbulent kinetic energy.

\subsubsection{Reynolds shear stress}

In Fig. 7 the normalised Reynolds shear stress, $\overline{u_{1} u_{3}} / U_{\infty}^{2}$, is shown for the nine configurations. As expected, both fluctuations are anti-correlated in the shear layer separated either from the bridge edge (when there are no windbreaks installed) or from the windbreak top. A strong positive correlation appears in two zones. The first one is the area close to the detachment point. The second zone corresponds to the recirculation region where the longitudinal mean velocity component is $U_{1} / U_{\infty}<0$ in Fig. 4.

\subsection{Flow patterns based on the streamlines from the mean average field}

In order to provide some additional information concerning the flow patterns of the mean averaged flow field, the streamlines corresponding to the mean velocity field $\mathbf{U}(\mathbf{x})=\left[U_{1}(\mathbf{x}), 0, U_{3}(\mathbf{x})\right]$, are computed and analysed. The tangent to the streamline $\mathbf{s}(\tau)$ at a location $\mathbf{x}_{0}$ is equal to the velocity vector in such location, i.e..

$\partial \mathbf{s}(\tau) / \partial \tau=\mathbf{U}\left(\mathbf{x}_{0}\right)$

The calculated streamlines of the mean velocity field are shown in previous figures (Figs. 4-7). The arrow size in the streamlines is proportional to the mean value of the local velocity magnitude.
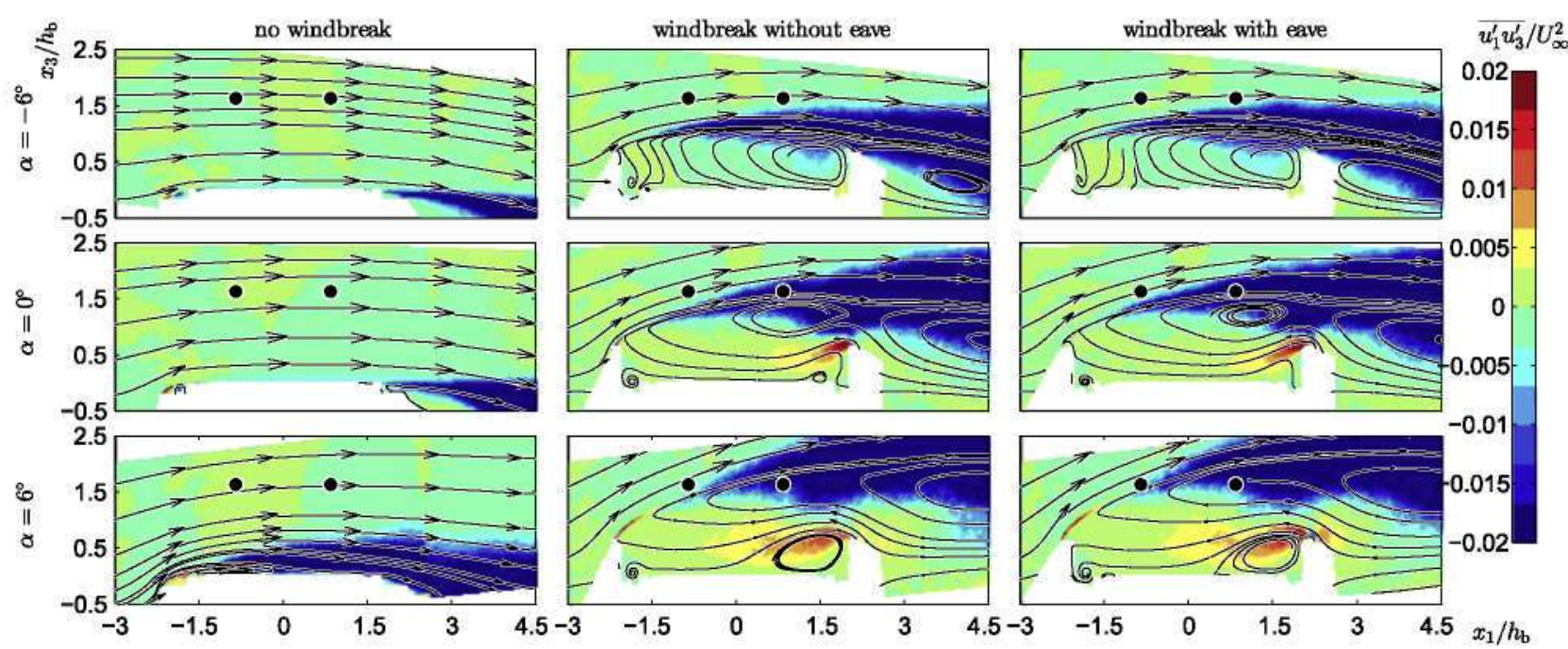

Fig. 7. Value of the Reynolds shear stress, $\overline{u_{1} u_{3}} / U_{\infty}^{2}$, and streamlines (solid lines) corresponding to the mean velocity field. Railway bridge equipped with the windbreak indicated in the column header. The angle of incidence of the flow is indicated in the first column. $16 \times 16$ pixel final interrogation window. The black circles indicate the contact wire locations (not present during experiments). The incident flow blows from left to right. 
The inclusion of a windbreak on the trailing edge prevents the vortex formed at the leading edge windbreak from being blown downstream from the bridge deck. Pournazeri and Princevac [83] studied by means of a water channel, how the inclusion of sound wall barriers may affect the flow patterns and the dispersion of vehicular emissions. Pournazeri and Princevac [83] include results obtained using particle image velocimetry of the velocity field, and it can be observed two effects. First, that even on flat terrain the inclusion of a second windbreak downstream locks the vortex between both windbreaks. Second, that a new vortex appears downstream the leeward windbreak. This effect can be observed even when the windbreak located in the leeward position is smaller than the windward one. The inclusion of the windbreaks, see Figs. 4-7, leads to the appearance of two vortex-like structures close to the railway track. One vortex-like structure is the separation bubble that is blocked by the leeward windbreak and cannot spread away from the bridge. The second one is a small vortexlike structure close to the windward fence, equivalent to region $\mathrm{F}$ in Fig. 1, with a similar topology to the one presented by Dong et al. [49] in their Fig. 12.

Besides the two vortex-like structures already described, when the angle of incidence is $\alpha=-6^{\circ}$, it can be observed that a third vortex appears downstream the bridge, due to the flow separated at the leeward fence. If the angle of incidence increases to $\alpha=0^{\circ}$ the vortex close to windward fence remains at the same location but the other two vortex-like structures are shifted upwards, just above the windbreak height. In this configuration it also appears a fourth vortex-like structure near to the leeward windbreak, close to the leeward railway track. When the angle of incidence increases to $\alpha=6$, the vortex-like structures close to the bridge deck remain at the same location, although the vortex close to the leeward track has growth in size. The other two vortex-like structures have been displaced upwards. If the angle of incidence is high enough, the vortex near the leeward contact wire will finally merge with the vortex-like structure located downstream the bridge.

\section{Vertical profiles of mean velocity and turbulence intensity}

In this section the vertical profiles of the mean velocity magnitude, $U=\left(U_{1}^{2}+U_{3}^{2}\right)^{0.5}$, and the turbulence intensity $I_{u}$ defined as

$I_{u}=\frac{\sigma_{u}}{U}$

are analysed, where $\sigma_{u}=\left(\overline{u^{2}}\right)^{0.5}$ is the standard deviation of the turbulent velocity component $u=\left(u_{1}^{2}+u_{3}^{2}\right)^{0.5}$. The values corresponding to the reference case are denoted as $U_{0}$ and $I_{u 0}$, where the reference case corresponds to the same angle of incidence but with no windbreaks installed on the bridge. Those variables are represented for the vertical lines ( $x_{1}=$ const.) that passes through the contact wire locations. Both variables, the mean wind speed and the turbulence intensity, for a given case (that is, given installed windbreak and the angle of incidence $\alpha$ ) are normalised with the value corresponding to the same location, the same angle of incidence, but without windbreaks installed. Therefore, the mean wind speed ratio at a particular location is defined as $U(\alpha, \mathbf{x}) / U_{0}(\alpha, \mathbf{x})$. In a similar manner, the turbulence intensity ratio is defined as $I_{u}(\alpha, \mathbf{x}) / I_{u 0}(\alpha, \mathbf{x})$.

\subsection{Vertical profiles at the windward track}

The reference mean wind speed, $U_{0}$, and the reference turbulence intensity, $I_{u 0}$, along the vertical line which contains the windward contact wire are shown in Fig. 8. The top of the windbreak is located at $x_{3} / h_{\mathrm{b}} \simeq 0.74$, and the contact wires at $x_{3} / h_{\mathrm{b}} \simeq 1.63$. When the flow approaches the bridge without windbreaks at an angle of incidence $\alpha=0^{\circ}$, it experiences a speed-up in the region above the railway track. The maximum flow speed value is found close to the ground because of the proximity of the leading edge of the ballast, where the flow separates. A decrease of the angle of incidence leads to a small decrease both on the wind velocity and the turbulence intensity.
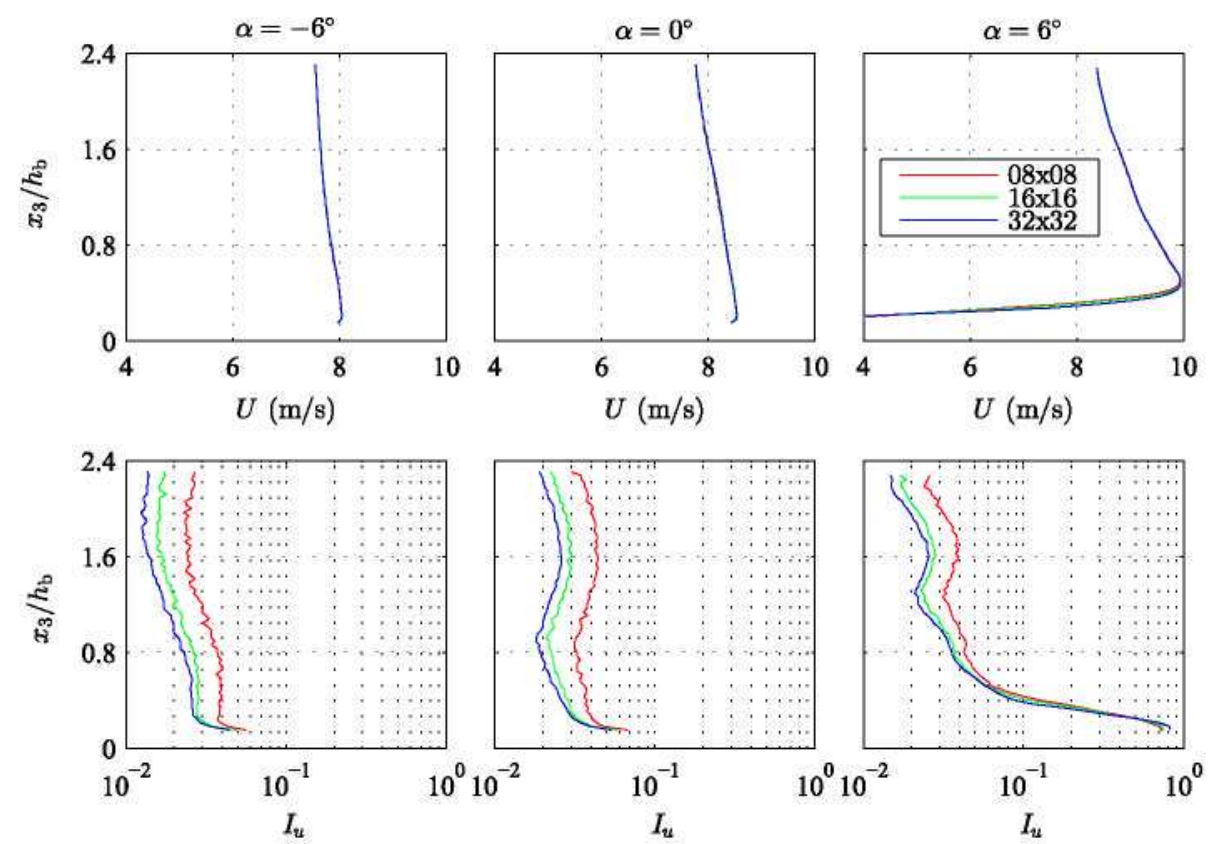

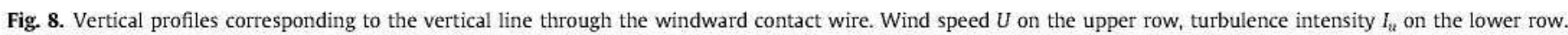
Railway bridge with no windbreaks, at three different angles of incidence of the flow, $\alpha=-6^{\circ}$ (left), $\alpha=0^{\circ}$ (center) and $\alpha=6^{\circ}$ (right). 
An increase in the angle of incidence of the flow (i.e. $\alpha=0^{\circ}$ or $\alpha=6^{\circ}$ ) leads to two different effects. The first effect is an increase in the mean velocity between the locations $x_{3} / h_{\mathrm{b}}=(0.5-1.5)$ due to the flow speed-up that occurs when the air flows across the windbreak. The second effect is an increase in the turbulence intensity on two different areas, in the area close to the ballast $\left(x_{3} / h_{\mathrm{b}}<0.5\right)$ mainly due to the velocity deficit, and near to the overhead location $\left(x_{3} / h_{\mathrm{b}} \sim 1.63\right)$. This increase in the turbulence intensity, more evident as $\alpha$ increases, is caused by the separated shear layer at the windward edge of the bridge, as was evidenced in Fig. 6.

Three final interrogation windows sizes have been considered during the PIV analysis, a $32 \times 32$ pixels, a $16 \times 16$ pixels and a $8 \times 8$ pixels square window. In the configuration herein analysed, a decrease on the final interrogation size leads to an increase of the estimated turbulence intensity value, most likely because the algorithms can capture smaller eddies on the flow, although spurious numerical effects are not discarded for the smallest interrogation window. A similar effect in the velocity fluctuation was reported by Lecordier et al. [82] due to an increase of the high frequency noise induced by the smaller number of particles used by the correlation algorithm. Henning and Ehrenfried [81] associate the differences in the flow statistics to the spatial averaging in the interrogation window, which acts as a low pass filter for the frequency response.

The wind speed ratio and turbulence intensity ratio for the configuration with a windbreak without eave are presented in Fig. 9. The values adopted at the windward contact wire location are summarised in Table 2 (velocity ratio) and Table 3 (turbulence intensity ratio). The inclusion of the windbreak induces a speedup in the flow near the contact wire location for angles of incidence of the flow $\alpha=-6^{\circ}$ and $\alpha=0^{\circ}$. The wind speed ratio reaches values about $U / U_{\infty} \simeq 1.1\left(\alpha=-6^{\circ}\right.$ and $\left.\alpha=0^{\circ}\right)$ and $U / U_{\infty} \simeq 1.0$ $\left(\alpha=6^{\circ}\right)$ in the upper region of the profiles. Zhu et al. [18] present the wind velocity profiles of a flat box girder bridge, and the road lanes closer to the leading edge present similar velocity ratios in the upper side of the wind profiles $\left(x_{3}>2 h_{\mathrm{wb}}\right)$. Also, despite the topological differences in the analysis of the wake of an isolated windbreak in flat terrain, Dong et al. [50] presents similar
Table 2

Value of the velocity ratio, $U / U_{0}$, at the windward contact wire location.

\begin{tabular}{cccccccc}
\hline & \multicolumn{3}{c}{ Windbreak } & & \multicolumn{3}{c}{ Windbreak+eave } \\
\cline { 2 - 4 } \cline { 6 - 8 } & $8 \times 8$ & $16 \times 16$ & $32 \times 32$ & & $8 \times 8$ & $16 \times 16$ & $32 \times 32$ \\
\hline$\alpha=-6^{\circ}$ & 1.10 & 1.10 & 1.10 & & 1.11 & 1.11 & 1.11 \\
$\alpha=0^{\circ}$ & 1.11 & 1.11 & 1.11 & & 1.13 & 1.12 & 1.12 \\
$\alpha=6^{\circ}$ & 0.97 & 0.97 & 0.98 & & 0.73 & 0.75 & 0.78 \\
\hline
\end{tabular}

speed-ups of the flow in the same region $\left(x_{3}>2 h_{\mathrm{wb}}\right)$ for a distance $x_{1}=1.5 h_{\mathrm{wb}}$ and $x_{1}=3 h_{\mathrm{wb}}$. The presence of the windbreak increases the turbulence intensity of the flow around the contact wire location with respect to the reference case, and values ranging from $I_{u} / I_{u 0} \simeq 1.5$ up to 3 (depending on $\alpha$ ) are found. In these configurations, an increase in the final interrogation window size also increases the estimated value of the turbulence intensity ratio. This trend is the opposite to the one observed for the absolute values of turbulence intensity for the reference case in Fig. 8. This effect is a consequence of the normalisation, i.e.. the smallest interrogation window leads to a larger increase of the turbulence intensity for the configuration with no windbreaks. In those configurations with a windbreak installed, the interrogation window size seems to have a negligible effect on the estimation of the turbulence intensity in the area below the contact wire. The results for the case of the inclusion of a windbreak with an eave is shown in Fig. 10. The wind velocity ratio and the turbulence intensity ratio present similar trends to those exhibited by the windbreak without eave. The inclusion of the eave shifts the shear layer upwards, and in consequence the region of the profiles with large gradients, both of wind velocity and turbulence intensity, is also slightly displaced upwards.

Concerning the wind profiles close to the railway track, there is a significant wind speed reduction compared to the unprotected case for heights below $x_{3} / h_{\mathrm{b}} \simeq 1.1\left(\alpha=-6^{\circ}\right)$, below $x_{3} / h_{\mathrm{b}} \simeq 1.4$ $\left(\alpha=0^{\circ}\right)$ and below $x_{3} / h_{b} \simeq 1.7\left(\alpha=6^{\circ}\right)$. The size of the region affected by the wind speed reduction depends on the value of the incidence angle. An increase in the angle of incidence of the flow shifts the wake produced by the windward fence upwards, and in consequence the size of this region is increased. The wind
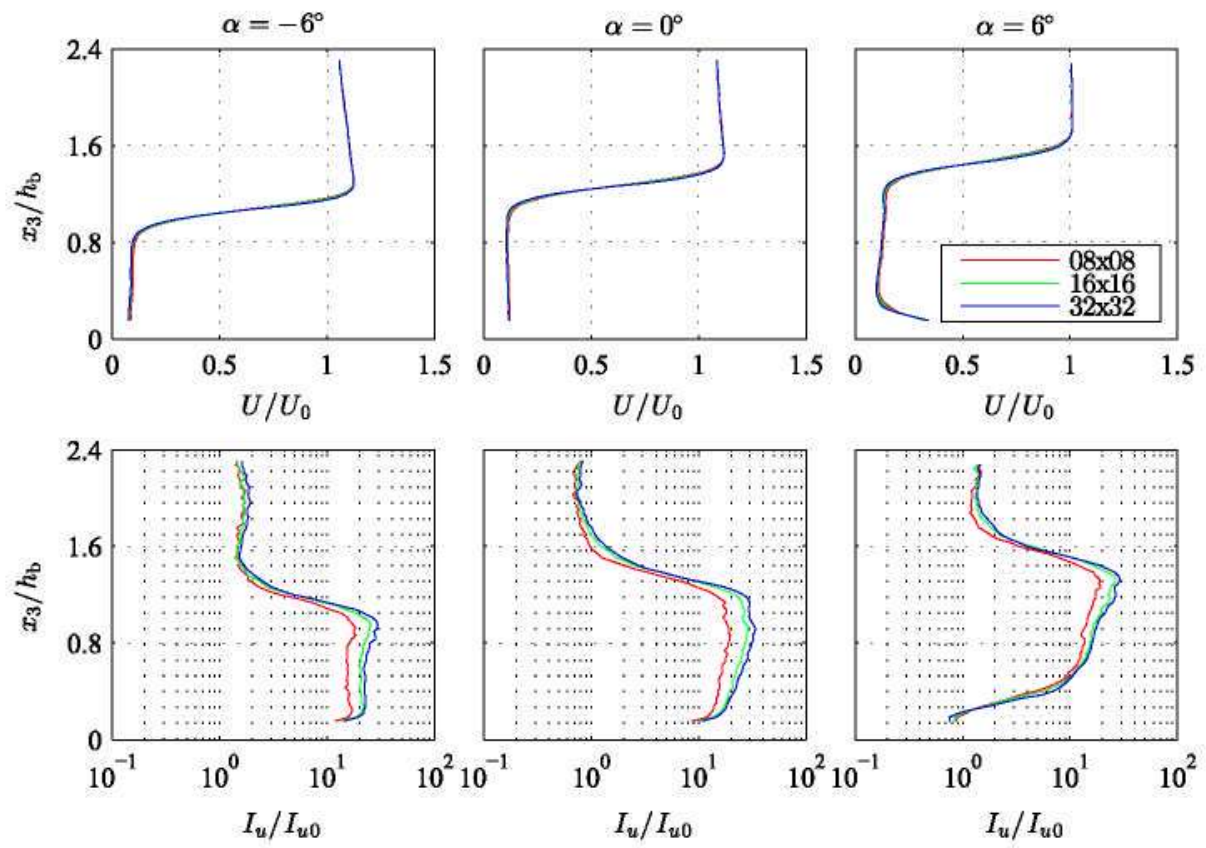

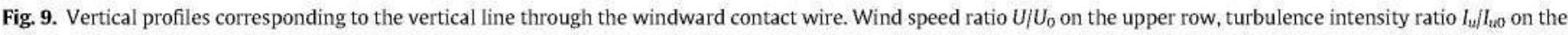
lower row. Railway bridge with windbreaks with no eaves, at three different angles of incidence of the flow, $\alpha=-6^{\circ}$ (left), $\alpha=0^{\circ}$ (center) and $\alpha=6^{\circ}$ (right). 

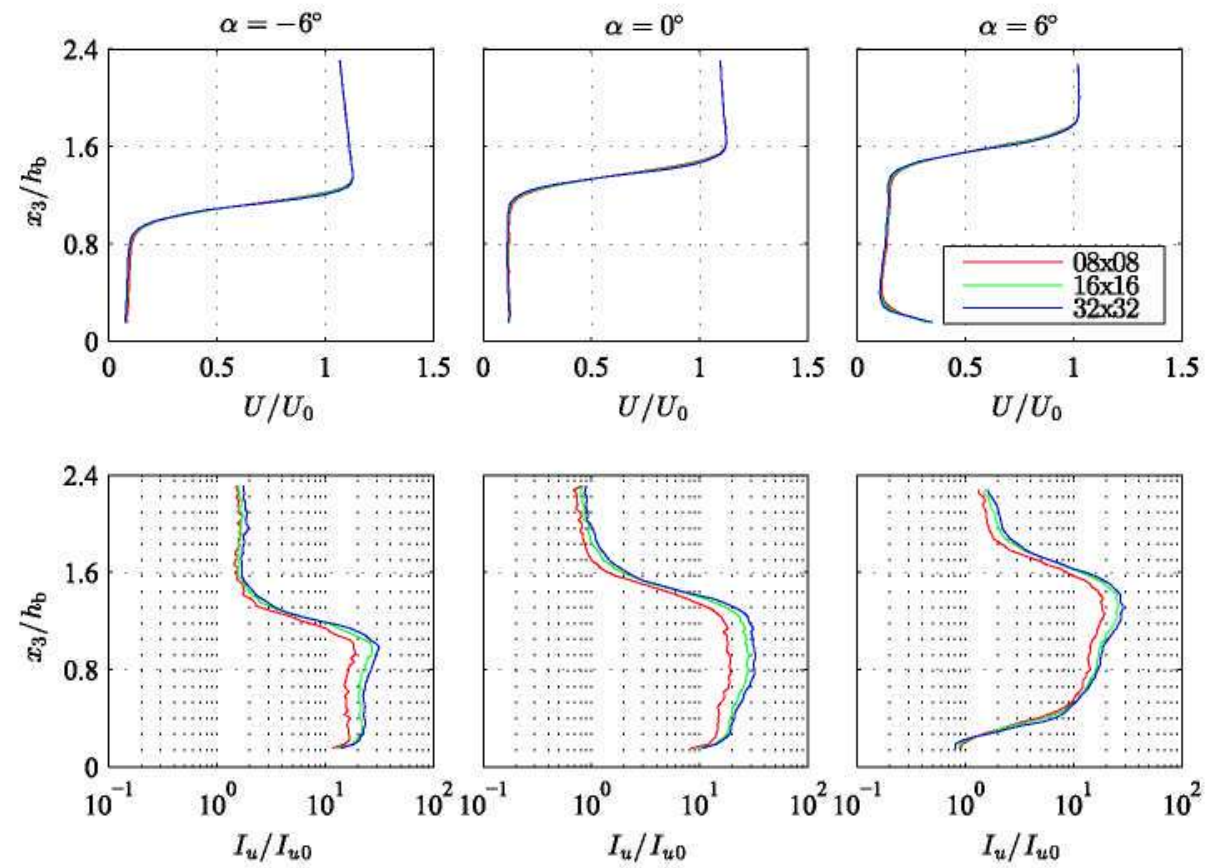

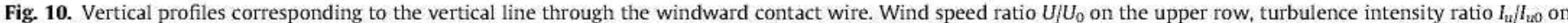
the lower row. Railway bridge with windbreaks equipped with eaves, at three different angles of incidence of the flow, $\alpha=-6^{\circ}$ (left), $\alpha=0^{\circ}$ (center) and $\alpha=6^{\circ}$ (right).

speed ratio is about $U / U_{\infty} \simeq 0.15$ for the three angles of incidence, although when the angle of incidence is $\alpha=6^{\circ}$ the wind speed ratio increases close to the ground due to the sudden drop of the reference velocity $U_{0}$. $[18,50]$ also present similar qualitative trends, although there exist some differences in the value of the wind velocity ratio. For similar reasons, the turbulence intensity ratio exhibits an increase in the area affected by the wind speed reduction, where values range from $I_{u} / I_{u 0} \simeq 20$ up to $I_{u} / I_{u 0} \simeq 30$.
Table 3

Value of the turbulence intensity ratio, $I_{u} / I_{v 0}$, at the windward contact wire location.

\begin{tabular}{cccccccc}
\hline & \multicolumn{3}{c}{ Windbreak } & & \multicolumn{3}{c}{ Windbreak + eave } \\
\cline { 2 - 4 } \cline { 7 - 8 } & $8 \times 8$ & $16 \times 16$ & $32 \times 32$ & & $8 \times 8$ & $16 \times 16$ & $32 \times 32$ \\
\hline$\alpha=-6^{\circ}$ & 1.54 & 1.52 & 1.64 & & 1.59 & 1.56 & 1.70 \\
$\alpha=0^{\circ}$ & 0.94 & 1.14 & 1.27 & & 1.23 & 1.64 & 1.87 \\
$\alpha=6^{\circ}$ & 2.80 & 3.35 & 3.32 & & 7.42 & 9.35 & 9.55 \\
\hline
\end{tabular}
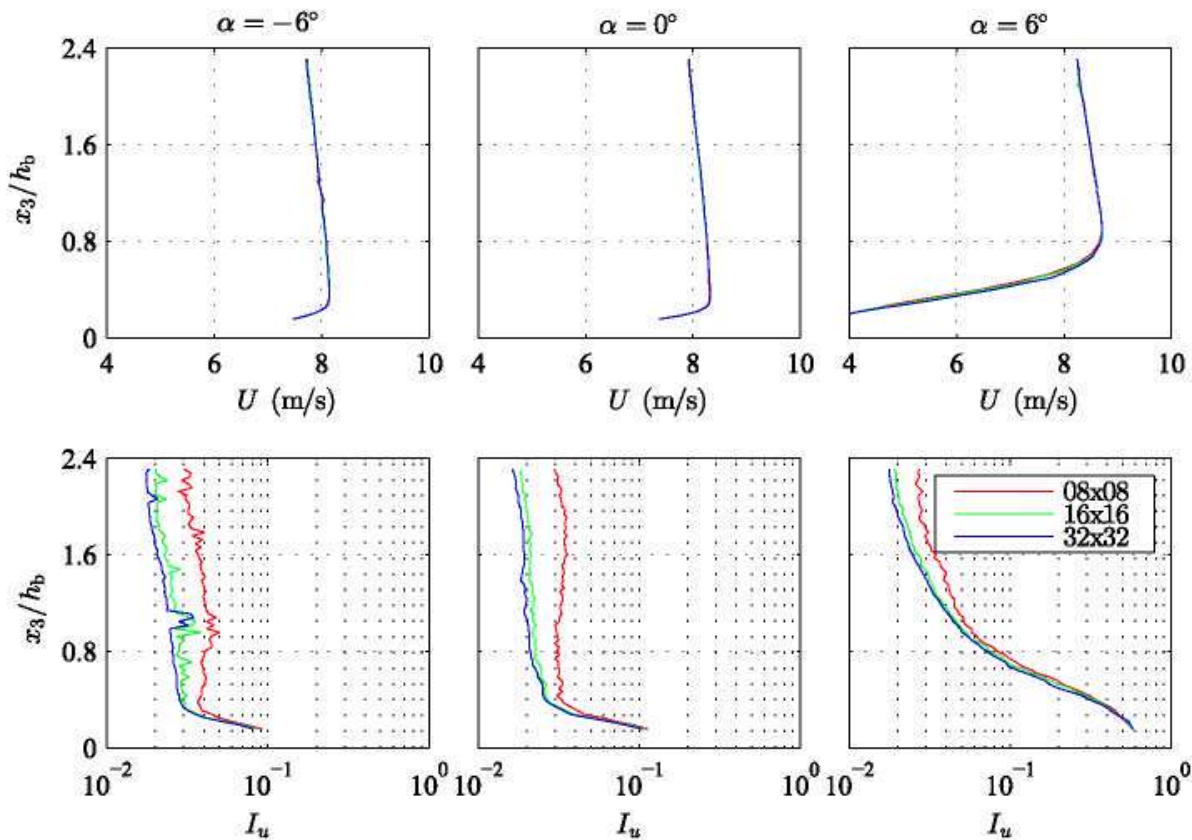

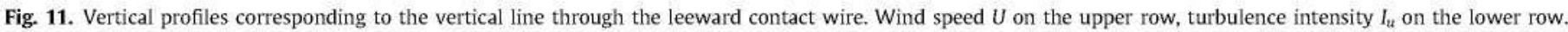
Railway bridge with no windbreaks, at three different angles of incidence of the flow, $\alpha=-6^{\circ}$ (left), $\alpha=0^{\circ}$ (center) and $\alpha=6^{\circ}$ (right). 

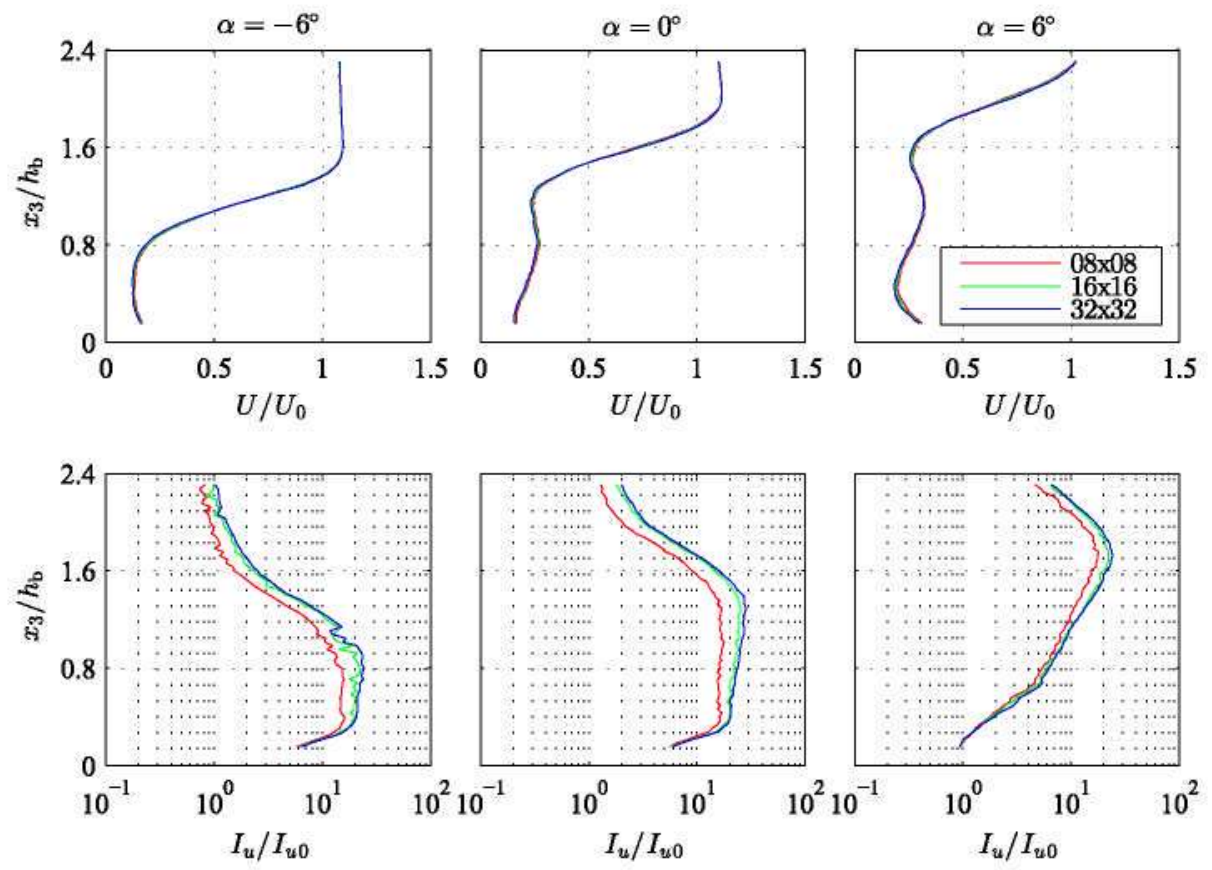

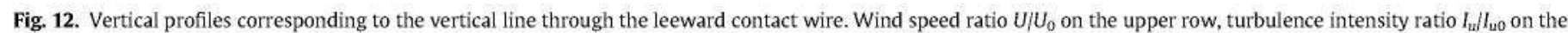
lower row. Railway bridge with windbreaks with no eaves, at three different angles of incidence of the flow, $\alpha=-6^{\circ}$ (left), $\alpha=0^{\circ}$ (center) and $\alpha=6^{\circ}$ (right).

\subsection{Vertical profile at the leeward track}

The reference vertical profiles (case without windbreaks) of the mean velocity magnitude, $U_{0}$, and the turbulence intensity, $I_{u 0}$, which contains the leeward contact wire are presented in Fig. 11. These profiles exhibit similar trends to those presented in Fig. 8 for the vertical profile at the windward track, for example, the incident flow also experiences a speed-up in the region above the railway track in the presence of the unprotected bridge. For the sake of briefness, only the main differences with the windward profile are commented in what follows.
The vertical profiles of the wind speed ratio, $U / U_{0}$, and the turbulence intensity ratio, $I_{u} / I_{u 0}$, for the model equipped with windbreaks are presented in Fig. 12 (windbreak without eave) and in Fig. 13 (windbreak with an eave). The experimental values obtained at the leeward contact wire location are summarised in Table 4 (velocity ratio) and Table 5 (turbulence intensity ratio). The qualitative trends are similar to those exhibited by the windward profiles. However, there exist two main qualitative differences, both of them in the upper region above $x_{3} / h_{\mathrm{b}} \simeq 1.6$. The first one corresponds to a significant reduction of the wind velocity ratio when the angle of incidence of the flow is $\alpha \geqslant 0^{\circ}$. The second
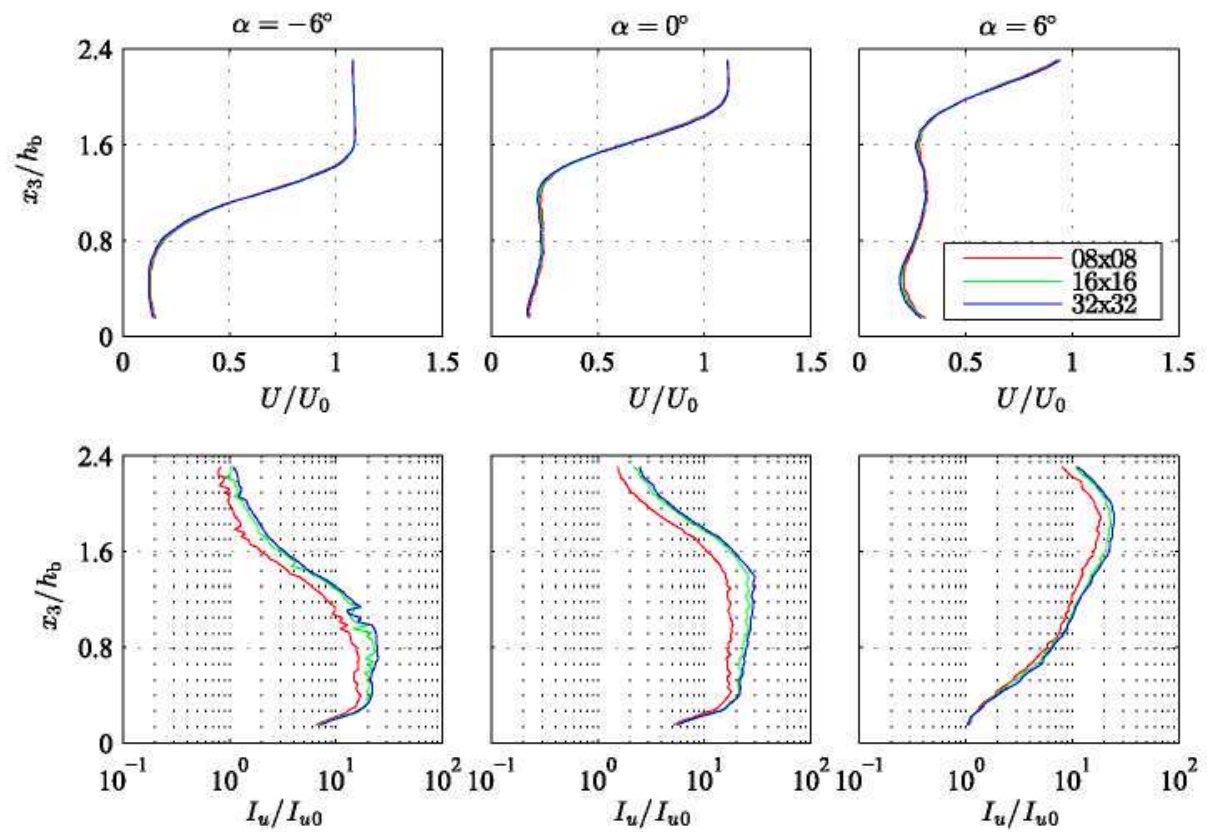

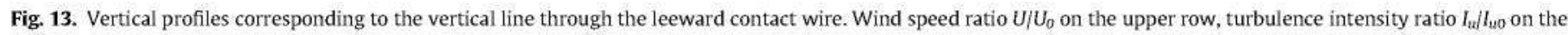
lower row. Railway bridge with windbreaks with eaves, at three different angles of incidence of the flow, $\alpha=-6^{\circ}$ (left), $\alpha=0^{\circ}$ (center) and $\alpha=6^{\circ}$ (right). 
Table 4

Value of the velocity ratio, $U / U_{0}$, at the leeward contact wire location.

\begin{tabular}{cccccccc}
\hline & \multicolumn{3}{c}{ Windbreak } & & \multicolumn{3}{c}{ Windbreak + eave } \\
\cline { 2 - 3 } \cline { 6 - 8 } \cline { 7 - 8 } & $8 \times 8$ & $16 \times 16$ & $32 \times 32$ & & $8 \times 8$ & $16 \times 16$ & $32 \times 32$ \\
\hline$\alpha=-6^{\circ}$ & 1.09 & 1.09 & 1.09 & & 1.09 & 1.09 & 1.09 \\
$\alpha=0^{\circ}$ & 0.77 & 0.78 & 0.80 & & 0.67 & 0.67 & 0.68 \\
$\alpha=6^{\circ}$ & 0.29 & 0.28 & 0.28 & & 0.29 & 0.28 & 0.27 \\
\hline
\end{tabular}

Table 5

Value of the turbulence intensity ratio, $I_{4} / I_{400}$, at the leeward contact wire location.

\begin{tabular}{cccccccc}
\hline & \multicolumn{3}{c}{ Windbreak } & & \multicolumn{3}{c}{ Windbreak+eave } \\
\cline { 2 - 4 } \cline { 7 - 8 } \cline { 7 - 8 } & $8 \times 8$ & $16 \times 16$ & $32 \times 32$ & & $8 \times 8$ & $16 \times 16$ & $32 \times 32$ \\
\hline$\alpha=-6^{\circ}$ & 1.49 & 2.06 & 2.29 & & 1.85 & 2.63 & 2.96 \\
$\alpha=0^{\circ}$ & 8.26 & 13.48 & 14.23 & & 9.98 & 16.59 & 17.73 \\
$\alpha=6^{\circ}$ & 16.93 & 21.36 & 22.70 & & 16.73 & 21.26 & 22.72 \\
\hline
\end{tabular}

difference is found in the increase of the turbulence intensity ratio when the angle of incidence of the flow is $\alpha \geqslant 0$. In the case of an angle of incidence $\alpha=0^{\circ}$ the region with higher values of turbulence intensity is located close to the contact wire location. These two differences can be explained with the analysis of the flow patterns in Section 3.3. In that configuration, as can be observed in Fig. 6, the leeward contact wire is immersed in the region with high values of the turbulent kinetic energy, $\bar{k}_{2 \mathrm{c}}$.

\section{Concluding remarks}

A simple approach to characterise the influence of a couple of solid windbreaks in the flow properties above a railway bridge has been proposed. Wind tunnel tests were conducted to measure the in-plane velocity components by the use of the mono-PIV technique. Obviously, the velocity field surrounding any model, either in wind tunnel either in a real case scenario, is threedimensional. However, the information obtained by this twodimensional study also provides preliminary information, such as the one concerning to the two component turbulent kinetic energy $\bar{k}_{2 \mathrm{C}}$, that may be useful to CFD modellers in order to stablish the proper hypotheses used for the turbulence closure problem.

The flow separated from a single solid windbreak, either on flat terrain or on the leading edge of the bridge, leads to the formation of a separation bubble (or vortex-like structure) in its wake. The inclusion of a second windbreak on the trailing edge restrains the location of this separation bubble to the bridge deck. As the angle of incidence of the flow increases, the trapped vortex is shifted upwards, and it eventually merges with the vortex produced at the wake of the bridge.

From a qualitative point of view, the vertical profiles of the wind speed reduction at the windward track are similar to the case of a single windbreak in flat terrain. The mean flow velocity around the windward contact wire location experiences a small speed-up, about $10 \%$, when the bridge is exposed to angles of incidence $\alpha=-6^{\circ}$ or $\alpha=0^{\circ}$. On the other hand, the mean flow velocity around the leeward contact wire location is slowed down below $80 \%$ for angles of incidence $\alpha=-6^{\circ}$ or $\alpha=0^{\circ}$. The wind speed is significantly reduced close to the bridge deck at height below the windbreak top both for the windward track $\left(U / U_{\infty}<0.15\right)$ and the leeward track $U / U_{\infty}<0.3$.

The shear layer produced by the windward fence leads to an increment of the turbulent kinetic energy. An increment on the angle of incidence raises the vertical distance from this shear layer to the railway track. The separation bubble locked between both windbreaks is also displaced upwards, close to the leeward contact wire, when the angle of incidence increases. Thus, the inclusion of the windbreak increases the turbulence intensity up to three times in the region near the windward contact wire and up to twenty times near the leeward one. The inclusion of an eave on the windbreak top has negligible effect on the qualitative trends presented by the flow patterns above the bridge deck. However, it raises slightly upwards the shear layer produced by the windward fence, increasing the turbulence intensity near the windward contact wire up to nine times the reference value. Three different sizes of the final interrogation window have been considered in the PIV analysis.

\section{Acknowledgement}

The authors wish to acknowledge the inspiring and living mind set of Jose Meseguer, who recently passed away after fighting against cancer during the last year of his life. He was the founder of the Instituto de Microgravedad Ignacio Da Riva (IDR/UPM). During his life he was involved both in experimental aerodynamics and in space oriented projects, such as the analysis of fluids in microgravity or the thermal control of subsystems in space vehicles. Up to the very moment of his death he kept an encouraging attitude towards research, working and teaching, that inspired not only this paper but also all the projects in which he was involved.

This work has been supported by the Spanish Ministerio de Ciencia e Innovación, under Contract TRA2009-13912-C012-01.

\section{References}

[1] Cook N. The designer's guide to wind loading of building structures - Part 1 Background, damage survey, wind data and structural classification. London: Butterworths; 1985.

[2] Holmes ]. Wind loading of structures. Third Edition. CRC Press; 2015. ISBN: 9781482229196.

[3] Johnson T. Strong wind effects on railway operations - 16th October 1987. ] Wind Eng Indust Aerodynam 1996;60:251-66.

[4] CENELEC. Copper and copper alloy grooved contact wires. Railway applications. Fixed installations. Electric traction. EN 50149:2012, European Committee for Electrotechnical Standarization; 2012.

[5] Alonso G, Meseguer J. A parametric study of the galloping stability of twodimensional triangular cross-section bodies. J Wind Eng Indust Aerodynam 2006;94(4):241-53. http://dx.doi.org/10.1016/i.jweia.2006.01.009. ISSN: 0167-6105Available from: http://www.sciencedirectcom/science/article/pii/ $\$ 016761050600016 \mathrm{X}$

[6] Alonso G, Valero E, Meseguer J. An analysis on the dependence on cross section geometry of galloping stability of two-dimensional bodies having either biconvex or rhomboidal cross sections. Eur J Mech - B/Fluids 2009;28 (2):328-34. http://dx doiorg/10.1016/ieuromechflu.2008.09.004. ISSN: 0997-7546Available from: http://www.sciencedirect.com/science/article/pii/ S0997754608001003.

[7] Ibarra D, Sorribes F, Alonso G, Meseguer J. Transverse galloping of twodimensional bodies having a rhombic cross-section. I Sound Vib 2014;333 (13):2855-65. ht/p://dx.doi.org/10.1016/jisv.2014.02.030. ISSN: 0022 460XAvailable from: http://www.sciencedirect.com/science/article/pii/ S0022460X14001576.

[8] Meseguer J, Sanz Andres A, Perales J, Pindado S. Aerodinámica civil. Cargas de viento en las edificaciones. S.A.U.: McGraw-Hill Interamericana de España; 2001.

[9] Scanlon T, Oldroyd A. An investigation into the attenuation of wind speed by the use of windbreaks in the vicinity of overhead wires. Proc Inst Mech Eng, Part F: J Rail Rapid Transit 2000;214(3):173-82. http://dxdoiorg/10.1243 0954409001531298. Available from: http://pif.sagepub.com/content/214/3 173.abstract.

[10] Stickland M, Scanlon T. An investigation into the aerodynamic characteristics of catenary contact wires in a cross-wind. Proc Inst Mech Eng, Part F: J Rail Rapid Transit 2001;215(4):311-8. http://dxdoi.org/10.1243 0954409011531602 . Available from: http://pif.sagepub.com/content/215/4/ 311.abstract.

[11] Stickland MT, Scanlon T], Craighead IA, Fernandez J. An investigation into the mechanical damping characteristics of catenary contact wires and their effect on aerodynamic galloping instability, vol. 217; 2003. p. 63-71. <http://pif. sagepub.com/content/217/2/63.abstract>.

[12] Cheli F, Corradi R, Rocchi D, Tomasini G, Maestrini E. Wind tunnel tests on train scale models to investigate the effect of infrastructure scenario. J Wind Eng Indust Aerodynam 2010;98:353-62. 
[13] European Railway Agency. Technical specification for interoperability relating to the rolling stock subsystem of the trans-European high-speed rail system. Official J EC. 2008/232/E; 2008.

[14] Bettle J, Holloway A, Venart J. A computational study of the aerodynamic forces acting on a tractor-trailer vehicle on a bridge in cross-wind. J Wind Eng Indust Aerodynam 2003;91(5):573-92. http://dx.doi.org/10.1016/50167-6105 Q2)00461-0. ISSN: 0167-6105Available from: http:// www.sciencedirect.com/science/article/pii/S0167610502004610.

[15] Diedrichs B. On computational fluid dynamics modelling of crosswind effects for high-speed rolling stock. Proc Inst Mech Eng, Part F: J Rail Rapid Transit 2003;217(3):203-26. http://dx.doi.org/10.1243/095440903769012902. Available from: http://pif.sagepub.com/content/217/3/203.abstract

[16] Khier W, Breuer M, Durst F. Flow structure around trains under side wind conditions: a numerical study. Comput Fluids 2000;29(2):179-95. bttpi//dx. doi.org/10.1016/S0045-7930(99)00008-0. ISSN: 0045-7930Available from: http://www.sciencedirect.com/science/article/pii/S0045793099000080.

[17] Chu C, Chang C, Huang C, Wu T, Wang C, Liu M. Windbreak protection for road vehicles against crosswind. J Wind Eng Indust Aerodynam 2013;116:61-9. htlp:/idx doiorg/101016/ijweia.2013.02.001. ISSN: 0167-6105Available from: http://www.sciencedirect.com/science/article/pii/S0167610513000500.

[18] Zhu L, Li L, Xu Y, Zhu Q. Wind tunnel investigations of aerodynamic coefficients of road vehicles on bridge deck. J Fluids Struct 2012;30:35-50. http://dx.doi. org/101016/2 fluidstructs 201109002 ISSN: 0889-9746Available from: http://www.sciencedirect.com/science/article/pii/S0889974612000060.

[19] Chen N, Li Y, Wang B, Su Y, Xiang H. Effects of wind barrier on the safety of vehicles driven on bridges. I Wind Eng Indust Aerodynam 2015;143:113-27. http:/dx.doiorg/10.1016/jiweia.2015.04.021. ISSN: 0167-6105Available from: http://www.sciencedirect.com/science/article/pii/S0167610515001166.

[20] Barcala M, Meseguer ]. An experimental study of the influence of parapets on the aerodynamic loads under cross wind on a two-dimensional model of a railway vehicle on a bridge. Proc Inst Mech Eng, Part F: J Rail Rapid Transit 2007;221(4):487-94. http:/dx.doi.org/10.1243/09544097JRRT53. Available from: http://pif.sagepub.com/content/221/4/487.abstract.

[21] Suzuki M, Tanemoto K, Maeda T. Aerodynamic characteristics of train/vehicles under cross winds. J Wind Eng Indust Aerodynam 2003;91(1-2):209-18. http:/idx.doi.org/10.1016/S0167-6105(02)00346-X. ISSN: 0167-6105Available from: http://www.sciencedirect.com/science/article/pii/S016761050200346X.

[22] Guo W, Xia H, Karoumi R, Zhang T, Li X. Aerodynamic effect of wind barriers and running safety of trains on high-speed railway bridges under cross winds. Wind Struct 2015;20(2):213-36. httpil/dx.doiorg/10.12989 Was. 2015.20.2.213.

[23] He X, Zou Y, Wang H, Han Y, Shi K. Aerodynamic characteristics of a trailing rail vehicles on viaduct based on still wind tunnel experiments. J Wind Eng Indust Aerodynam 2014;135:22-33. http://dx.doi.org/10.1016/j.jweia.2014.10.004. ISSN: 0167-6105Available from: http://www.sciencedirect.com/science article/pii/S0167610514001974.

[24] Tomasini G, Giappino S, Cheli F, Schito P. Windbreaks for railway lines: wind tunnel experimental tests. In: Proceedings of the institution of mechanical engineers, Part F: J Rail Rapid Transit. doi:http://dx.doi.org/10.1177/ 0954409715596191. 0954409715596191 ,abstract>.

[25] Kikuchi $K$, Suzuki M. Study of aerodynamic coefficients used to estimate critical wind speed for vehicle overtuming. J Wind Eng Indust Aerodynam 2015;147:1-17. http://dx.doi.org/10.1016/j.jweia 2015.09.003. ISSN: 0167 6105Available from: http://www.sciencedirect.com/science/article/pii S0167610515002196.

[26] Cheli F, Giappino S, Rosa L, Tomasini G, Villani M. Experimental study on the aerodynamic forces on railway vehicles in presence of turbulence. I Wind Eng Indust Aerodynam 2013;123(Part B):311-6. http://dx.doi.org/10,1016/i. iweia.2013.09.013. ISSN: 0167-6105Available from: http:] www.sciencedirect.com/science/article/pii/S0167610513002018.

[27] Campi P, Palumbo A, Mastrorilli M. Effects of tree windbreak on microclimate and wheat productivity in a Mediterranean environment. Eur J Agronomy 2009;30(3):220-7. http://dx.dol.org/10.1016/j.eja.2008.10.004. ISSN: 11610301Available from: http://www.sciencedirect.com/science/article/pii/ \$1161030108001196.

[28] Dierickx W. Field evaluation of windbreak protection for orchards. Biosyst Eng 2003:84(2):159-70. htto//dx doiorg/101016/51537-5110(02)00263-5. ISSN : 1537-5110Available from: http://www.sciencedirect.com/science/article/pii/ S1537511002002635.

[29] Foereid B, Bro R, Mogensen V, Porter J. Effects of windbreak strips of willow coppice-modelling and field experiment on barley in Denmark. Agric Ecosyst Environ 2002;93(1-3):25-32. htip://dxdoi.org/10.1016/S0167-8809(02)000075. ISSN: 0167-8809Available from: http://www.sciencedirect.com/science/ article/pii/S0167880902000075.

[30] Schwartz R, Fryrear D, Harris B, Bilbro ], Juo A. Mean flow and shear stress distributions as influenced by vegetative windbreak structure. Agric Fores Meteorol 1995;75(1-3):1-22. bttpi//dx doiorg/10.1016/0168-1923(94)02206Y. ISSN: 0168-1923Available from: http://www.sciencedirect.com/science/ article/pii/016819239402206V.

[31] Alhajraf S. Computational fluid dynamic modeling of drifting particles at porous fences. Environ Modell Softw 2004;19(2):163-70. http://dx.doi.org. 101016/S1364-8152(03)00118-X. ISSN: 1364-8152Available from: http:] www.sciencedirect.com/science/article/pii/\$136481520300118X. modelling of Wind Erosion and Aeolian Processes.
[32] Lee S, Park K, Park C. Wind tunnel observations about the shelter effect of porous fences on the sand particle movements. Atmos Environ 2002:36 (9):1453-63. http://dx.doi.org/10.1016/S1352-2310(01)00578-7. ISSN: 13522310Available from: http://www.sciencedirect.com/science/article/pii/ $\$ 1352231001005787$

[33] Yeh C, Tsai C, Yang R. An investigation into the sheltering performance of porous windbreaks under various wind directions. J Wind Eng Indust Aerodynam 2010;98(10-11):520-32. http://dx.dol.org/10.1016/i. iweia.2010.04.002. ISSN: 0167-6105Available from: http: / www.sciencedirect.com/science/article/pii/S0167610510000322.

[34] Peterka J, Tan L. Wind loads on heliostats and parabolic dish collectors. Tech. rep. SERI/STR-253-3431. Colorado State University; 1988.

[35] Peterka J, Hosoya N, Bienkiewicz B, Cermak J. Wind load reduction for heliostats. Tech. rep. SERI/STR-253-2859. Colorado State University; 1986.

[36] Peterka J, Tan L, Bienkiewcz B, Cermak J. Mean and peak wind load reduction on heliostats. Tech. rep. SERI/STR-253-3212. Colorado State University; 1987.

[37] Torres García E, Ogueta-Gutiérrez M, Ávila S, Franchini S, Herrera E, Meseguer J. On the effects of windbreaks on the aerodynamic loads over parabolic solar troughs. Appl Energy 2014;115(0):293-300. htip://dx.doiorg/10.1016/i. apenergy.2013.11.013. ISSN: 0306-2619Available from: http:/] www.sciencedirect.com/science/article/pii/S0306261913009069.

[38] Kwon H, Park Y, Lee D, Kim M. Wind tunnel experiments on Korean high-speed trains using various ground simulation techniques. I Wind Eng Indust Aerodynam 2001;89(13):1179-95. http://dx.doi.org/10.1016/\$0167-6105(01) 00107-6. ISSN: 0167-6105Available from: http:/] www.sciencedirect.com/science/article/pii/S0167610501001076.

[39] Kwon S, Kim D, Lee S, Song H. Design criteria of wind barriers for traffic. Part 1: Wind barrier performance. Wind Struct 2011;14(1):55-70. http://dx.doi.org/ 10.12989iwas.2011.14.1.055.

[40] Zheng S. Research on the wind load parameters and the wind fences behaviour for wind fences of railway bridge. In: Proceedings of seventh Asia-Pacific conference on wind engineering.

[41] Barcala M, Meseguer ]. Visualization study of the influence of parapets on the flow around a train vehicle under cross-wind. In: Proceedings of comprail 2008, eleventh international conference on computer system design and operations in the railway and other transit systems. Wessex: WITPress; 2008.

[42] Avila-Sanchez S, Meseguer J, Lopez-Garcia O. Turbulence intensity on catenary contact wires due to parapets placed on a double track bridge. J Wind Eng Indust Aerodynam 2010;98(10-11):504-11. http://dx.doi.org/10.1016/i. iweia.2010.03.003. ISSN: 0167-6105Available from: http:// www.sciencedirect.com/science/article/pii/S0167610510000309.

[43] Avila-Sanchez S, Pindado S, Lopez-Garcia O, Sanz-Andrés A. A. Wind-tunnel analysis of the aerodynamic loads on rolling stock over railway embankments: the effect of shelter windbreaks. Sci World J 2014;2014. http://dx. doi.orgi 101155/2014/421829. Article ID 421829.

[44] Allori D, Bartoli G, Mannini C. Wind tunnel tests on macro-porous structural elements: a scaling procedure. J Wind Eng Indust Aerodynam 2013;123(Part B):291-9. http://dxudoiorg/10.1016/i.jweia 2013.09.011. ISSN: 01676105Available from: http://www.sciencedirect.com/science/article/pii/ S0167610513001992.

[45] Guan D, Zhang Y, Zhu T. A wind-tunnel study of windbreak drag. Agric Forest Meteorol 2003;118(1-2):75-84. http:lidx doi.org/10.1016/50168-1923(03) 00069-8. ISSN: 0168-1923Available from: http:// www sciencedirect com/science/article/pii/S0168192303000698.

[46] Boldes U, Colman J, Marañon Di leo J. Field study of the flow behind single and double row herbaceous windbreaks. J Wind Eng Indust Aerodynam 2001;89 (7-8):665-87. httpi//dx.doi.org/101016/S0167-6105(01)00065-4. ISSN: 0167-6105Available from: http://www.sciencedirect.com/science/article/pii/ \$0167610501000654.

[47] Flesch TK, Wilson JD. Wind and remnant tree sway in forest cutblocks: 1. Measured winds in experimental cutblocks. Agric Forest Meteorol 1999;93 (4):229-42. http://dxdoiorg/10,1016/S0168-1923(98)00112-9. ISSN: $0168-$ 1923Available from: http://www.sciencedirect.com/science/article/pii/ \$0168192398001129.

[48] Hagen 1, Skidmore E. Turbulent velocity fluctuations and vertical flow as affected by windbreak porosity. Trans Am Soc Agric Eng 1971:14:634 7.

[49] Dong Z, Luo W, Qian G, Wang H. A wind tunnel simulation of the mean velocity fields behind upright porous fences. Agric Forest Meteorol 2007:146(12):82-93. http://dx.doi.org/10.1016/i.agrformet.2007.05.009. ISSN: 01681923Available from: http://www.sciencedirect.com/science/article/pii/ S0168192307001438.

[50] Dong Z, Luo W, Qian G, Lu P, Wang H. A wind tunnel simulation of the turbulence fields behind upright porous wind fences. J Arid Environ 2010;74 (2):193-207, http://dx.doi.org/10.1016/j.jaridenv.2009.03.015. ISSN: 01401963Available from: http://www.sciencedirect.com/science/article/pii/ \$0140196309000937.

[51] Lee S, Lim H. A numerical study on flow around a triangular prism located behind a porous fence. Fluid Dynam Res 2001;28(3):209-21. http://dx.doi.org. 10.1016/S0169-5983(00)00030-7. ISSN: 0169-5983Available from: http:/ www.sciencedirect.com/science/article/pii/S0169598300000307.

[52] Yaragal S, Govinda Ram H, Murthy K. An experimental investigation of flow fields downstream of solid and porous fences. J Wind Eng Indust Aerodynam 1997;66(2):127-40. bttp://dx.doiorg/10.1016/S0167-6105(97)00015-9. ISSN: 0167-6105Available from: http://www.sciencedirect.com/science/article/pii/ S0167610597000159. 
[53] Hong S, Lee I, Seo I. Modelling and predicting wind velocity patterns for windbreak fence design. J Wind Eng Indust Aerodynam 2015;142:53-64. http://dx.doi.org/10.1016/i.jweia.2015.03.007. ISSN: 0167-6105Available from: http://www.sciencedirect.com/science/article/pii/S0167610515000677.

[54] Fang F, Wang D. On the flow around a vertical porous fence. J Wind Eng Indust Aerodynam 1997;67-68(0):415-24. http://dx.dol.org/10.1016/S0167-6105 (97)00090-1. ISSN: 0167-6105Available from: http://www.sciencedirect. $\mathrm{com} /$ science/article/pii/S0167610597000901.

[55] Maruyama T. Large eddy simulation of turbulent flow around a windbreak. J Wind Eng Indust Aerodynam 2008;96(10-11):1998-2006. http://dx.doi.org/ 10.1016/i.jweia.2008.02.062. ISSN: 0167-6105Available from: http:// www sciencedirectcom/science/article/pii/S0167610508000792.

[56] Santiago J, Martín F, Cuerva A, Bezdenejnykh N, Sanz-Andrés A. Experimental and numerical study of wind flow behind windbreaks. Atmos Environ 2007;41 (30):6406-20. http://dx.doi.org/10.1016/i.atmosenv.2007.01.014. ISSN: 1352 2310Available from: http://www.sciencedirect.com/science/article/pii/ \$1352231007000829.

[57] Speckart S, Pardyjak E. A method for rapidly computing windbreak flow field variables. J Wind Eng Indust Aerodynam 2014;132(0):101-8. hup:/idxdoi org/10.1016/jiwweia.2014.07.001. ISSN: 0167-6105Available from: http:// www.sciencedirect.com/science/article/pii/S0167610514001287.

[58] Wang H, Takle E. On shelter efficiency of shelterbelts in oblique wind. Agric Forest Meteorol 1996;81(1-2):95-117. http://dx.doi.org/10.1016/0168-1923 (95)02311-9. ISSN: 0168-1923Available from: http://www.sciencedirect. com/science/article/pii/0168192395023119.

[59] Cornelis W, Gabriels D. Optimal windbreak design for wind-erosion control. J Arid Environ 2005;61(2):315-32. http://dxdoi.org/10.1016/jjaridenv:2004. 10.005. ISSN: 0140-1963Available from: http://www.sciencedirect. com/science/article/pii/S0140196304002010.

[60] Dierickx W, Cornelis W, Gabriels D. Wind tunnel study on rough and smooth surface turbulent approach flow and on inclined windscreens. Biosyst Eng 2003;86(2):151-66. http://dx doiorg/10 1016/S1537-5110(03)00120-X. ISSN: 1537-5110Available from: http://www.sciencedirect.com/science/article/pii/ \$153751100300120X.

[61] Sorribes F, Lopez-Garcia O, Sanz-Andrés A, Cuerva A, Meseguer J, Martínez A, Vega E, Avila-Sanchez S, Mascaraque A, Martínez J. The effect of windbreaks on railway overheads subject to cross-winds at O Eixo Viaduct. In: Pombo J. editor. Proceedings of the first international conference on railway technology: research, development and maintenance, Paper 151, Civil-Comp. Stirlingshire, UK: Civil-Comp Press; 2012. p. 1-12. httpi/dxdoiorg/10.4203/ccp 98.151. ISBN: 978-1-905088-52-2Available from: http://www.ctresources.info/ ccp/paper.html?id=6800.

[62] Lee S, Kim H. Laboratory measurements of velocity and turbulence field behind porous fences. J Wind Eng Indust Aerodynam 1999;80(3):311-26. http://dx. doiorg/10.1016/50167-6105(98)00193-7. ISSN: 0167-6105Available from: http://www.sciencedirect.com/science/article/pii/S0167610598001937.

[63] Shiau B. Measurement of the Reynolds stress structure behind multiple windbreaks across-wind. J Wind Eng Indust Aerodynam 1995;54-55:561-71. http://dx.doi.org/10.1016/0167-6105(94)00072-1. ISSN: 0167-6105Available from: http://www.sciencedirect.com/science/article/pii/016761059400072l

[64] Kozmar H. Procino L, Borsani A, Bartoli G. Sheltering efficiency of wind barriers on bridges. J Wind Eng Indust Aerodynam 2012;107-108:274-84. bttp://dx. doiorg/10.1016/j.jweia.2012.04.027. ISSN: 0167-6105Available from: http:// www.sciencedirect.com/science/article/pii/S0167610512001298.

[65] Kozmar H, Procino L, Borsani A, Bartoli G. Optimizing height and porosity of roadway wind barriers for viaducts and bridges. Eng Struct 2014;81:49-61. http://dx.doiorg/101016/i.engstruct.2014.09.029. ISSN: 0141-0296Available from: http://www.sciencedirect.com/science/article/pii/S0141029614005665.

[66] Lee ], Lee S. PIV analysis on the shelter effect of a bank of real fir trees. J Wind Eng Indust Aerodynam 2012;110:40-9. htp://dxdoiorg/101016/1
jweia.2012.07.003.ISSN: 0167-6105Available from: http://www.sciencedirect. com/science/article/pii/S0167610512002073.

[67] Plate E. The aerodynamics of shelter belts. Agric Meteorol 1971;8:203-22 http:/dx doiorg/10.1016/0002-1571(71)90109-9. ISSN: 0002-1571Available from: http://www.sciencedirect.com/science/article/pii/0002157171901099.

[68] Sanz Andrés A, Guerra Sierra A, Bezdenejnykh N, Cuerva Tejero A. Barreras cortavientos y otras medidas atenuadoras de las emisiones de polvo en los puertos. V.A. Impresores; 2002.

[69] Guo W, Wang Y, Xia H, Lu S. Wind tunnel test on aerodynamic effect of wind barriers on train-bridge system. Sci China Technol Sci 2015;58(2):219-25. http://dx.doi.org/10.1007/s11431-014-5675-1. ISSN: 1869-1900Available from: http:/dxdoi.org/10.1007/s11431-014-5675-1.

[70] Xiang $\mathrm{H}$, Li Y, Chen B, Liao $\mathrm{H}$. Protection effect of railway wind barrier on running safety of train under cross winds. Adv Struct Eng 2014;17 (8):1177-88. htto:/idx doiorg/10.1260/1369-4332.178.1177

[71] Sesma 1, Sanchez G, Vinolas ], Rivas A, Avila-Sanchez S. A two-dimensional computational parametric analysis of the sheltering effect of fences on a railway vehicle standing on a bridge and experiencing crosswinds. Proc Inst Mech Eng, Part F: J Rail Rapid Transit 2015;229(2):186-200. http:/idxdoiorg? 10.1177/0954409713504395. Available from: http://pif.sagepub.com/content/ 229/2/186.abstract.

[72] Andrés del Valle Pérez A, Carriazo Lara A, Simón-Talero Muñoz J, Chico López P. Viaducto sobre el río Ulla. Hormigón y Acero 2010;61(258):7-23. ISSN: 0439. 5689.

[73] Pardo de Vera Posada 1, Pantaleón Prieto M, Ramos Gutiérrez O, Ortega Carreras G, Martínez García J. Viaductos sobre Río Deza y Anzo 2. Hormigón y Acero 2011;62(259):61-74. ISSN: 0439-5689.

[74] Avila-Sanchez S, Meseguer J, Lopez-Garcia O, Fernández J, Martínez A Intensidad de Turbulencia en la Catenaria Inducida por Barreras Cortavientos en Viaductos. In: Actas del IX Congreso de Ingeniería del Transporte CIT 2010. INSIA. Universidad Politécnica de Madrid; 2010. ISBN: 978-84-96398-41-

[75] Yeow T, Cuerva-Tejero A, Perez-Alvarez J. Reproducing the Bolund experiment in wind tunnel. Wind Energy 2015;18:153-69. http://dx.doi.org/10.1002 we.1688. Available from: http://dx.doi.org/10.1002/we.1688.

[76] Raine J, Stevenson D. Wind protection by model fences in a simulated atmospheric boundary layer. J Wind Eng Indust Aerodynam 1977:2 (2):159-80. htto:/dxdoiorg/10 1016/0167-6105(77)90015-0. ISSN: 0167 6105Available from: http://www.sciencedirect.com/science/article/pii/ 0167610577900150 .

[77] Irwin P. Bluff body aerodynamics in wind engineering. ] Wind Eng Indust Aerodynam 2008;96:701-12.

[78] Larose G, D'Auteuil A. On the Reynolds number sensitivity of the aerodynamics of bluff bodies with sharp edges. I Wind Eng Indust Aerodynam 2006:94:365-76.

[79] ESDU. Blockage corrections for bluff bodies in confined flows. ESDU 80024 Engineering Science Data Unit; 1998

[80] Raffel M, Willert C, Wereley S, Kompenhans ]. Particle image velocimetry, a practical guide. Berlin, Heidelberg: Springer; 2007.

[81] Henning A, Ehrenfried K. On the accuracy of one-point and two-point statistics measured via high-speed PIV. In: 14th International symposium on applications of laser techniques to fluid mechanics. p. 1-16.

[82] Lecordier B, Demare D, Vervisch L, Réveillon J, Trinité M. Estimation of the accuracy of PIV treatments for turbulent flow studies by direct numerical simulation of multi-phase flow. Measure Sci Technol 2001;12(9):1382. Available from: http://stacks.iop.org/0957-0233/12/i=9/a=302.

[83] Pournazeri S, Princevac M. Sound wall barriers: near roadway dispersion under neutrally stratified boundary layer. Transport Res Part D: Transport Environ 2015;41:386-400. http://dx.doi.org/10.1016/i.trd.2015.09.025. ISSN 1361-9209Available from: http://www.sciencedirect.com/science/article/pii/ \$1361920915001492. 